\title{
Nadir toprak elementlerinin birincil ve ikincil kaynaklardan üretimi
}

\author{
Production of rare earth elements from primary and secondary resources
}

\author{
Oktay CELEP*1,a, Ersin Y. YAZICI ${ }^{1, b}$, Hacı DEVECi ${ }^{1, c}$ \\ ${ }^{I}$ Karadeniz Teknik Üniversitesi, Mühendislik Fakültesi, Maden Mühendisliği Bölümü, Hydromet B\&PM Araştırma Grubu, 61080, \\ Trabzon
}

• Geliş tarihi / Received: 07.07.2020 • Düzeltilerek geliş tarihi / Received in revised form: 28.11.2020 • Kabul tarihi / Accepted: 06.12.2020

\section{$\ddot{O} z$}

Nadir toprak elementleri (NTE), yüksek sıcaklığa, aşınmaya, korozyona karşı dirençli olan yüksek teknolojik ürünlerin üretiminde kullanılmaktadır. Yüksek ekonomik değere ve temin edilme riskine sahip olmaları nedeniyle kritik hammaddeler olarak listelenmektedirler. Elektrikli-elektronik cihazlar (cep telefonu, bilgisayar, TV gibi), şarj edilebilir piller (NiMH piller), modern tıp cihazları (MR cihazı gibi), rüzgâr türbinleri, katalitik dönüştürücüler, motorlar (uçak, elektrikli araç motorları), cam ve seramik sanayi, petrol rafinerisi, güneş panelleri gibi ileri teknolojik ürünlerin uygulandığı pek çok alanda kullanılmaktadırlar. Hibrit ve elektrikli araçların ve rüzgâr türbinlerin yaygınlaşmasıyla beraber nadir toprak elementlerine olan talep giderek artmaktadır. NTE içeren pek çok mineral bulunmasına karşın endüstriyel öneme sahip en yaygın mineraller bastnazit, monazit ve ksenotimdir. Bu minerallerin dışında mıknatıslar, floresan lambalar, katalizörler ve şarj edilebilir piller de, nadir toprak elementi içeren önemli ikincil kaynaklardır. Bu çalışmada, NTE'nin kritik hammadde olarak önemi, potansiyeli, birincil ve ikincil kaynaklardan üretim teknolojileri değerlendirilmiştir. Minerallerden ve ikincil kaynaklardan geri kazanım yöntemleri akım şemalarıyla beraber tartışılmıştır. Önemli bir ikincil kaynak olan Nd-Fe-B mıknatıslar, nikel-metal hidrür piller ve floresan lamba atıkları detaylı olarak irdelenmiştir.

Anahtar kelimeler: Cevher zenginleştirme, Geri kazanım, Hidrometalurji, Kritik hammadde, Liç, Nadir toprak elementleri (NTE)

\begin{abstract}
Rare earth elements (REE) are utilized in the production of high-tech products that are resistant to high temperature, abrasion, and corrosion. They are termed critical raw materials due to their high economic value and risk of availability. REE are used in many fields where advanced technological products such as electric-electronic devices (mobile phones, computers, TVs), rechargeable batteries (NiMH batteries), modern medical devices (MR), wind turbines, catalytic converters, engines (aircraft, electric vehicle engines), glass and ceramic industry oil refinery, solar panels are applied. With the widespread use of hybrid and electric vehicles and wind turbines, the demand for rare earth elements is increasing. Although there are many REE-bearing minerals, the most common minerals of industrial interest are bastnäzite, monazite and xenotime. In addition to these minerals, magnets, fluorescent lamps, catalysts and rechargeable batteries are also secondary sources containing important rare earth elements. In this study, their importance, potential, and production technologies of primary and secondary sources are evaluated. Recovery methods from minerals and secondary sources are discussed with flow charts. Important secondary sources such as Nd-Fe-B magnets, nickel-metal hydride batteries, and fluorescent lamp waste are discussed in detail.
\end{abstract}

Keywords: Mineral processing, Recycling, Hydrometallurgy, Critical raw material, Leaching, Rare earth elements (REE)

\footnotetext{
*a Oktay CELEP, ocelep@ktu.edu.tr, Tel: (0462) 37741 18, orcid.org/0000-0001-9024-4196

${ }^{\mathrm{b}}$ orcid.org/0000-0002-8711-0784 $\quad{ }^{\mathrm{c}}$ orcid.org/0000-0003-4105-0912
} 


\section{Giriş}

Teknolojik gelişimin sağlanabilmesi ve ülkeler arası rekabet gücünün artırılması amacıyla katma değeri yüksek yeni teknolojilerin geliştirilmesi gerekmektedir. Bu hedef doğrultusunda öncelikli alanlarda hammadde ihtiyacını sağlamak için nadir toprak elementleri (NTE) gibi kritik hammaddelerin aranmas1, üretilmesi ve ileri teknolojik ürünlerde kullanılmasına yönelik çalışmalara öncelik verilmesi gerekmektedir. Artan hammadde talebi ve tüketiminin karşılanabilmesi için doğal kaynakların korunması, sürdürülebilir geri dönüşüm/kazanım olanaklarının araştırılması ve ileri teknolojik ürünlerde kullanılması önemli olacaktır.

NTE, yüksek sıcaklığa, aşınmaya, korozyona karşı dirençli ileri teknolojik malzeme üretiminde çok farklı sektörlerde kullanılmaları nedeniyle stratejik elementler olarak değerlendirilmektedir. Benzer kimyasal özelliğe sahip 15 adet lantanit grubu elementlerinden ve bunlara ilave olarak skandiyum ve itriyumu içeren toplam 17 elementten oluşmaktadır (Tablo 1) (Krishnamurthy ve Gupta, 2016). Lantan (La), Seryum (Ce), Praseodim (Pr), Neodimyum (Nd), Prometyum (Pm) ve Samaryum (Sm) hafif nadir toprak elementleri olarak; Evropiyum (Eu), Skandiyum ( $\mathrm{Sc})$, İtriyum $(\mathrm{Y})$, Gadolinyum (Gd), Terbiyum ( $\mathrm{Tb}$ ), Disporsiyum (Dy), Holmiyum (Ho), Erbiyum (Er), Tulyum (Th), İterbiyum $(\mathrm{Yb})$ ve Lutesyum $(\mathrm{Lu})$ ise ağır nadir toprak elementleri olarak siniflandırılmaktadır (Connelly vd., 2005; Jha vd., 2016). NTE üretiminin çoğu bastnazit, monazit ve ksenotim gibi minerallerden sağlanmakla beraber oksitli, karbonatlı, silikatlı ve fosfatlı bileşikleri içeren çok sayıda (250'den fazla) mineralde farklı konsantrasyonlarda bulunmaktadırlar (Tablo 2) (Vijayan vd., 1989; Zhang ve Edwards, 2012; Jordens vd., 2013). Minerallerden NTE'nin kazanımında flotasyon, manyetik ve gravite zenginleştirme yöntemlerinin yanı sıra hidrometalurjik yöntemler de kullanılmaktadır (Krishnamurthy ve Gupta, 2016).

NTE, elektrikli-elektronik cihazlar (cep telefonu, bilgisayar, TV gibi), şarj edilebilir piller (NiMH piller), modern tıp cihazları (MR cihazı gibi), katalitik dönüştürücüler, motorlar (uçak, hibrit araçlar, rüzgar türbinleri), cam ve seramik sanayi, petrol rafineri, güneş panelleri gibi ileri teknolojik pek çok cihaz ve ekipmanın üretiminde yaygın bir şekilde kullanılmaktadırlar (Tablo 3) (Binnemas vd., 2013; Krishnamurthy ve Gupta, 2016; USGS, 2020). Neodimyum, terbiyum ve disporsiyum gibi elementler elektrikli cihazların motorlarında, rüzgâr türbinlerinde ve bilgisayar sabit disklerinde kullanılan NdFeB miknatıs üretiminde kullanılırlar. İtriyum, renkli televizyon, yakıt hücreleri ve flüoresan lambaların üretiminde yaygın olarak kullanılan temel bir bileşendir. Seryum ve lantan elementleri çoğunlukla katalitik dönüştürücülerde kullanılır. Evropiyum kompakt flüoresan ampullerde, televizyonlarda ve cep telefonu ekranlarında kullanılır. Cep telefonlarında (kamera, hoparlör, batarya, elektronik devrelerinde, ekran ve titreşim sistemlerinde) neodimyum, lantan, praseodim, terbiyum, disporsiyum, gadolinyum, itriyum, evropiyum olmak üzere sekiz adet NTE kullanılmaktadır. ScAI, Sc-Mg, Y-AI, Y-Mg ve Nd-Mn gibi nadir toprak elementi alaşımları, yüksek sıcaklıklarda korozyon direncini arttırmaları ve oksitlenmeyi önleyici özelliklerinden dolayı metalürjide de yaygın olarak kullanılmaktadırlar (Y1ldız, 2016; MTA, 2017).

Türkiye'de MTA tarafından yapılan çalışmalar sonucunda Eskişehir'de (Beylikahır, Kızılcaören) bastnasit-florit-barit yatağ yatak 4 milyon ton rezerve sahip olup ortalama $\% 3$ NTE içermektedir (Kul vd., 2008). Ayrıca Malatya-Kuluncak yöresi de önemli bir NTE potansiyeli olarak görülmektedir. Bölgede 100 ton $\% 24$ tenörlü britolit cevherleşmesi olduğu tahmin edilmektedir (MTA, 2017). Ayrica, Isparta (Çanaklı), Konta (Mortaş-Doğankuzu) ve Malatya'da (Sofular) önemli NTE cevherleşmeleri bulunmaktadır (Kurşun ve Terzi, 2018; Akıska vd., 2019).

Dünya emtia arzı ve talebi göz önüne alınarak çeşitli kuruluşlar (Avrupa Komisyonu, ABD Enerji Bakanlığ 1$)$ tarafından kritik hammaddeler belirlenmekte ve hazırlık eylem planları yayımlanmaktadır. 2017 yılında yayımlanan en son raporda verilen 27 hammadde, temin edilme riski açısından kritik hammaddeler olarak adlandırılmışlardır. $\mathrm{Bu}$ rapora, 2014 yılında yayımlanan listenin dışında 9 yeni hammadde ilave edilmiştir. Buna duruma göre nadir toprak elementlerinin tamamı kritik hammadde olarak tanımlanmıştır (EC, 2017 ve 2019).

Hibrit/elektrikli araçların ve rüzgâr türbinlerinin kullanımının yaygınlaşmasıyla beraber nadir toprak elementlerine olan talep giderek artmaktadır. Bu artışa bağlı olarak 2017 yılındaki 132.000 ton olan dünya NTE üretimi, son 2 yılda artarak yaklaşık 213.000 ton'a ulaşmıştır. 2019 yılı verilerine göre toplam NTE üretiminin yaklaşık $\% 62$ 'sini Çin üretmekte olup onu sirasiyla $\mathrm{ABD}$ (\%12) ve Avustralya (\%10) takip etmektedir. Toplam 120 milyon ton olan dünya NTE rezervinin $\% 36$ 'sına Çin sahip olup Brezilya ve Vietnam $\% 18$ 'lik paya sahiptir (Tablo 4) (USGS, 2020). 
Tablo 1. Nadir toprak elementleri ve bazı özellikleri (Gschneidner ve Daane, 1988, Gschneidner, 1990; Tran, 1991; Jackson ve Christiansen, 1993; Gschneidner vd., 1995; McGill, 2000; Kanazawa ve Kamitani, 2006; Zhang ve Edwards, 2012; Krishnamurthy ve Gupta, 2016; Dostal, 2017)

\begin{tabular}{|c|c|c|c|c|c|c|c|}
\hline Element & Simge & $\begin{array}{c}\text { Atom } \\
\text { Numarası }\end{array}$ & $\begin{array}{c}\text { Atom } \\
\text { Ağırlığı }\end{array}$ & $\begin{array}{l}\text { Yoğunluk, } \\
\text { gr/cm } / \mathrm{cm}^{3}\end{array}$ & $\begin{array}{c}\text { Ergime } \\
\text { noktası, }{ }^{\circ} \mathrm{C}\end{array}$ & $\begin{array}{c}\text { Kaynama } \\
\text { noktası, }{ }^{\circ} \mathrm{C}\end{array}$ & $\begin{array}{c}\text { Vicker's sertliği } \\
\left(\mathrm{kg} / \mathrm{mm}^{2}\right)\end{array}$ \\
\hline Skandiyum & $\mathrm{Sc}$ & 21 & 44.95 & 2.989 & 1541 & 2831 & 85 \\
\hline İtriyum & $\mathrm{Y}$ & 39 & 88.90 & 4.469 & 1522 & 3338 & 38 \\
\hline Lantan & $\mathrm{La}$ & 57 & 138.90 & 6.146 & 918 & 3457 & 37 \\
\hline Seryum & $\mathrm{Ce}$ & 58 & 140.11 & 8.160 & 798 & 3426 & 24 \\
\hline Praseodim & $\operatorname{Pr}$ & 59 & 140.90 & 6.773 & 931 & 3515 & 37 \\
\hline Neodimyum & $\mathrm{Nd}$ & 60 & 144.24 & 7.008 & 1021 & 3068 & 35 \\
\hline Prometyum & $\mathrm{Pm}$ & 61 & 145.00 & 7.264 & 1042 & - & - \\
\hline Samaryum & $\mathrm{Sm}$ & 62 & 150.30 & 7.520 & 1074 & 1791 & 45 \\
\hline Evropiyum & $\mathrm{Eu}$ & 63 & 151.96 & 5.244 & 822 & 1597 & 17 \\
\hline Gadolinyum & Gd & 64 & 157.25 & 7.901 & 1313 & 3266 & 57 \\
\hline Terbiyum & $\mathrm{Tb}$ & 65 & 158.92 & 8.230 & 1356 & 3223 & 46 \\
\hline Disporsiyum & Dy & 66 & 162.50 & 8.551 & 1412 & 2562 & 42 \\
\hline Holmiyum & Но & 67 & 164.93 & 8.795 & 1474 & 2695 & 42 \\
\hline Erbiyum & $\mathrm{Er}$ & 68 & 167.26 & 9.066 & 1529 & 2863 & 44 \\
\hline Tulyum & $\mathrm{Tm}$ & 69 & 168.93 & 9.321 & 1545 & 1947 & 48 \\
\hline İterbiyum & $\mathrm{Yb}$ & 70 & 173.04 & 6.966 & 819 & 1194 & 21 \\
\hline Lutesyum & $\mathrm{Lu}$ & 71 & 174.97 & 9.841 & 1663 & 3395 & 77 \\
\hline
\end{tabular}

Tablo 2. Nadir toprak elementlerini içeren önemli mineraller (Ferron vd., 1991; Jackson ve Christiansen, 1993; McGill, 2000; Kanazawa ve Kamitani, 2006; Long vd., 2010 ve 2012; Dushyanthaa vd., 2020)

\begin{tabular}{|c|c|c|}
\hline Mineral & Formül & NTE içeriği, \% \\
\hline Aeskinit & $(\mathrm{Ce}, \mathrm{Ca}, \mathrm{Th})(\mathrm{Ti}, \mathrm{Nb})_{2} \mathrm{O}_{6}$ & $\% 15.5-19.5 \mathrm{Ce}_{2} \mathrm{O}_{3} ; \% 0.9-4.5(\mathrm{Y}, \mathrm{Er})_{2} \mathrm{O}_{3}$ \\
\hline Bastnazit & $(\mathrm{Ce}, \mathrm{La}, \mathrm{Pr})\left(\mathrm{CO}_{3}\right) \mathrm{F}$ & \%36.9-40.5 $\mathrm{Ce}_{2} \mathrm{O}_{3} ; \% 36.3-36.6(\mathrm{La}, \mathrm{Pr} . . .)_{2} \mathrm{O}_{3}$ \\
\hline Öksenit & $(\mathrm{Y}, \mathrm{Ce}, \mathrm{Ca}, \mathrm{U}, \mathrm{Th})(\mathrm{Ti}, \mathrm{Nb}, \mathrm{Ta})_{2} \mathrm{O}_{6}$ & $\% 18.2-27.7(\mathrm{Y}, \mathrm{Er})_{2} \mathrm{O}_{3} ; \% 16-30(\mathrm{Ce}, \mathrm{La} \ldots . .)_{2} \mathrm{O}_{3}$ \\
\hline Fergusonit & $(\mathrm{Y}, \mathrm{Sr}, \mathrm{Ce}, \mathrm{U})(\mathrm{Nb}, \mathrm{Ta}, \mathrm{Ti}) \mathrm{O}_{4}$ & $\% 31-42 \mathrm{Y}_{2} \mathrm{O}_{3} ; \% 0.9-6(\mathrm{Ce}, \mathrm{La} \ldots)_{2} \mathrm{O}_{3} ; \% 0-14 \mathrm{Er}_{2} \mathrm{O}_{3}$ \\
\hline Gadolinit & $(\mathrm{Y}, \mathrm{Ce})_{2} \mathrm{FeBe}_{2} \mathrm{Si}_{2} \mathrm{O}_{10}$ & $\% 30.7-46.5 \mathrm{Y}_{2} \mathrm{O}_{3} ; \% 5.23(\mathrm{Ce}, \mathrm{La} \ldots . .)_{2} \mathrm{O}_{3}$ \\
\hline Loparit & $(\mathrm{Na}, \mathrm{Ca}, \mathrm{Ce}, \mathrm{Sr})_{2}(\mathrm{Ti}, \mathrm{Ta}, \mathrm{Nb})_{2} \mathrm{O}_{6}$ & $\% 32-34(\mathrm{Ce}, \mathrm{La} \ldots . .)_{2} \mathrm{O}_{3}$ \\
\hline Monazit & $(\mathrm{Ce}, \mathrm{La} \ldots) \mathrm{PO}_{4}$ & $\% 50-68(\mathrm{Ce}, \mathrm{La} \ldots . .)_{2} \mathrm{O}_{3}$ \\
\hline Ortit & $(\mathrm{Ca}, \mathrm{Ce})_{2}(\mathrm{Al}, \mathrm{Fe})_{3} \mathrm{Si}_{3} \mathrm{O}_{12}[\mathrm{O}, \mathrm{OH}]$ & $\% 0-6 \mathrm{Ce}_{2} \mathrm{O}_{3} ; \% 0-7 \mathrm{La}_{2} \mathrm{O}_{3} ; \% 0-8 \mathrm{Y}_{2} \mathrm{O}_{3}$ \\
\hline Parisit & $\mathrm{Ca}(\mathrm{Ce}, \mathrm{La} \ldots)_{2}\left(\mathrm{CO}_{3}\right) \mathrm{F}_{2}$ & $\% 26-31 \mathrm{Ce}_{2} \mathrm{O}_{3} ; \% 27.3-30.4(\mathrm{La}, \mathrm{Nd} \ldots)_{2} \mathrm{O}_{3} ; \% 8 \mathrm{Y}$ \\
\hline Piriorit & $(\mathrm{Y}, \mathrm{Er}, \mathrm{Ca}, \mathrm{Th})(\mathrm{Ti}, \mathrm{Nb})_{2} \mathrm{O}_{6}$ & $\% 21.1-28.7(\mathrm{Y}, \mathrm{Er})_{2} \mathrm{O}_{3} ; \% 3.7-4.3 \mathrm{Ce}_{2} \mathrm{O}_{3}$ \\
\hline Samarskit & $(\mathrm{Y}, \mathrm{Er}, \mathrm{U}, \mathrm{Ce}, \mathrm{Th})_{4}(\mathrm{Nb}, \mathrm{Ta})_{6} \mathrm{O}_{2}$ & $\begin{array}{l}\text { \%6.4-14.5 } \mathrm{Y}_{2} \mathrm{O}_{3} ; \% 2.7-13.4 \quad \mathrm{Er}_{2} \mathrm{O}_{3} ; \% 0.25-3.2 \mathrm{Ce}_{2} \mathrm{O}_{3} ; \% 0.37-1 \mathrm{La}_{2} \mathrm{O}_{3} \text {; } \\
\% 0.74-4.2(\mathrm{Pr}, \mathrm{Nd})_{2} \mathrm{O}_{3}\end{array}$ \\
\hline Torit & $\mathrm{ThSiO}_{4}$ & $\% 0.37-1 \mathrm{La}_{2} \mathrm{O}_{3} ; \% 0.74-4.2(\mathrm{Pr}, \mathrm{Nd})_{2} \mathrm{O}_{3}$ \\
\hline Ksenotim & $\mathrm{YPO}_{4}$ & $\% 52-62 \mathrm{Y}_{2} \mathrm{O}_{3}$ \\
\hline İtroserit & $(\mathrm{Ca}, \mathrm{Y}, \mathrm{Ce}, \mathrm{Er}) \mathrm{F}_{2} \cdot 3 \mathrm{H}_{2} \mathrm{O}$ & $\% 8.5-11.5 \mathrm{Ce} ; \% 14.3-37.7 \mathrm{Y}$ \\
\hline
\end{tabular}

Tablo 3. Nadir toprak elementlerinin kullanım alanları (Greinacher, 1981; Jackson ve Christiansen, 1993; Long vd., 2010; Gschneidner, 2011a.b; Zhang ve Edwards, 2012; Haque vd., 2014; Dushyanthaa vd., 2020)

\begin{tabular}{ll}
\hline Kullanım alanları & Kullanıldığı ekipman, cihaz ya da sistemler \\
\hline Mıknatıslar & $\begin{array}{l}\text { Motorlar, disk sürücüler ve motorları, jeneratörler, mikrofon ve hoparlörler, manyetik rezonans } \\
\text { görüntüleme cihazı (MRI), fren sistemi ve otomobil parçaları, iletişim sistemleri, rulmanlar, } \\
\text { mikrodalga tüpleri, soğutma sistemleri, alaşımlar }\end{array}$ \\
Katalizörler & $\begin{array}{l}\text { Petrol rafinasyonu, kimyasal prosesler, katalitik dönüştürücüler, mazot katkısı, endüstriye atık } \\
\text { temizleme sistemleri }\end{array}$ \\
Elektronik cihazlar & Ekranlar (CRT; PDP; LCD), lazerler, medikal görüntüleme cihazları, fiber optik, sensörler \\
Cam & Parlatma bileşikleri, optik camlar, optik termal sensörler, termal aynalar \\
Seramik & Kapasitörler, sensörler, renklendiriciler, sintilatör \\
Alaşımlar & Hidrojen depolama (NiMH piller, yakıt hücreleri), çelik, dökme demir, süper alaşımlar \\
Diğer & Su arıtma, floresan lambalar, pigmentler, gübre, tıbbi izleme, kaplamalar \\
\hline
\end{tabular}


Tablo 4. Dünya nadir toprak elementleri rezerv ve üretim miktarları (USGS, 2020)

\begin{tabular}{lccc}
\hline Ülke & \multicolumn{2}{c}{ Üretim, ton } & Rezerv, \\
& $\mathbf{2 0 1 8}$ & $\mathbf{2 0 1 9}$ & $\mathbf{x 1 0}^{\mathbf{3}}$ ton \\
\hline ABD & 18.000 & 26.000 & 1.400 \\
Avustralya & 21.000 & 21.000 & 3.300 \\
Brezilya & 1.100 & 1.000 & 22.000 \\
Burundi & 630 & 600 & - \\
Çin & 120.000 & 132.000 & 44.000 \\
G. Afrika & - & - & 790 \\
Grönland & - & - & 1.500 \\
Hindistan & 2.900 & 3.000 & 6.900 \\
Kanada & - & - & 830 \\
Madagaskar & 2.000 & 2.000 & - \\
Myanmar & 19.000 & 22.000 & - \\
Rusya & 2.700 & 2.700 & 12.000 \\
Tanzanya & - & - & 890 \\
Tayland & 1.000 & 1.800 & - \\
Vietnam & 920 & 900 & 22.000 \\
Diğer & 60 & - & 310 \\
Toplam & $\sim \mathbf{1 9 0 . 0 0 0}$ & $\mathbf{2 1 3 . 0 0 0}$ & $\mathbf{1 1 6 . 0 0 0}$ \\
\hline
\end{tabular}

\section{Birincil ve ikincil kaynaklardan nadir toprak elementlerinin kazanımı}

NTE içeren pek çok mineral bulunmasına karşın NTE üretiminin yapıldığ 1 en yaygın mineraller monazit, bastnazit ve ksenotimdir (Tablo 2). Bunlarla birlikte iyon adsorbe eden killer de önemli bir NTE kaynağıdır (Gschneidner, 2011b; Jha vd., 2016; Zhang ve Edwards, 2012; Haque vd., 2014). Loparit, Rusya'da NTE üretiminde kullanılsa da dünya toplam üretimdeki payı düşüktür $(<\% 3)$ (Kosynkin vd., 1993). Bu minerallerin dışında atık mıknatıslar, floresan lambalar, katalizörler ve şarj edilebilir piller de önemli NTE içeren ikincil kaynaklardır. Ayrıca, kömür ve uçucu küller de potansiyel NTE kaynağı olarak değerlendirilmektedir (Kashiwakura vd., 2013; Franus vd., 2015; Taggart vd., 2017; Dai ve Finkelman, 2018; Kurşun ve Terzi, 2018; U.S. Geological Survey, 2019).

\subsection{Birincil kaynaklardan nadir toprak elementlerinin kazanımı}

Cevherlerden NTE kazanımında yaygın bir şekilde flotasyon, manyetik, elektrostatik ve gravite ayırma (sallantılı masa, spiraller) yöntemleri veya bu yöntemlerin kombinasyonları kullanılmaktadır. NTE içeren cevherler genellikle barit, florit, kalsit, silikat ve demir mineralleriyle birlikte bulunurlar. $\mathrm{Bu}$ gang mineralleri, zenginleştirme işlemlerini zorlaştırmaktadırlar.

\subsubsection{Fiziksel/fizikokimyasal yöntemler}

Mountain Pass (ABD, California) ve Bayan Obo (Çin) dünyanın en büyük NTE üretimi yapılan bastnazit/monazit içeren cevher yataklarıdır. Cevherlerden NTE'lerin yanı sira manyetit, florit, hematit ve niyobyum oksitler de yan ürün olarak kazanılmaktadır. Bastnazit ve monazit içeren Bayan Obo (Çin) cevheri, 1927 y1lında demir cevheri olarak işletilmeye başlanmış olup Çin'in en büyük demir yatağıdır (1,5 milyar ton rezerv). Bayan Obo tesisinde üç farklı proses akışı bulunmaktadır (Şekil 1). Cevher -74 $\mu$ m'a $\left(d_{90}\right)$ ögütüldükten sonra flotasyon uygunlanmakta, kaba flotasyon işleminde $\mathrm{pH}$ düzenleyici olarak $\mathrm{Na}_{2} \mathrm{CO}_{3}$, demir ve silikatları bastırmak için $\mathrm{Na}_{2} \mathrm{SiO}_{3}$ ve toplayıc1 olarak sodyum tuzu (parafin sabunu) kullanılmaktadır. Kaba flotasyon ve gravite zenginleştirme sonrasında \%80 NTE kazanımı elde edilmektedir. Nihai olarak \% 47 NTE içeren bir monazit konsantresi ve \%68 NTE içeren bastnazit konsantresi üretilmektedir (Jiake ve Xiangyong, 1984).

NTE içeren minerallerin yoğunluklarının yüksek $\left(4-7 \mathrm{~g} / \mathrm{cm}^{3}\right)$ olması ve genel olarak düşük manyetik alınganlık ve çok düşük elektrik iletkenliklerine sahip olmaları nedeniyle silikat gibi gang minerallerinden ayrılmasında gravite yöntemleri yaygın bir şekilde kullanılmaktadır (Ferron vd., 1991). Sahil kumlarından (\%30 ağır mineral) monazitin kazanımında (\%80-90 ağır mineral kazanımı), konik ayırıcılar, spiral ayırıcılar ve sallantılı masa kullanılmaktadır (Moustafa ve Abdelfattah, 2010). Gravite zenginleştirme sonrasında manyetik ve elektrostatik ayırma yöntemleriyle yüksek tenörlü $(\% 97)$ monazit konsantresi elde edilmektedir. Diğer bazı cevherlerden, laboratuvar ölçekte gravite yöntemleriyle NTE kazanımının başarılı bir şekilde gerçekleştirildiği çalışmalar da mevcuttur (Guy vd., 2000; Özbayoglu ve Atalay, 2000). Özbayoğlu ve Atalay (2000), Beylikahır bastnazit cevherinden aşındırma/dağıtma ve siklon kullanarak elde edilen ön konsantreden (\%28 NTE, \% 72,6 verim) Mozley multi-gravity seperatör (MGS) ile \%35,5 NTE tenörlü bir konsantre elde etmişlerdir. NTE içeren cevherlerden monazit ve ksenotim gibi paramanyetik mineralleri zirkon ve rutil gibi manyetik olmayan gang minerallerinden ayırmak amacıyla manyetik ayırma yaygın bir şekilde kullanılmaktadır (Ito vd., 1991; Ferron vd., 1991; Tran, 1991; Chan, 1992; Gao ve Chen, 2010; Zhang ve Edwards, 2012). Ayrıca, düşük alan şiddetli manyetik ayırma ile ferromanyetik demir oksit gang mineralleri de uzaklaştırılmaktadır. İnce tanelerin ayrilmasinda $(<100 \mu \mathrm{m})$ ise flotasyon tekniği tercih edilmektedir (Rosenblum ve Brownfield, 1999). Yoğunlukları ve manyetik özellikleri birbirine benzer gang minerallerinden (örn. iletken ilmenit) monazit ve ksenotimin 
ayrılmasında elektrostatik ayırma yöntemi kullanılmaktadır (Ferron vd., 1991; Higashiyama ve Asano, 2007; Zhang ve Edwards, 2012). Loparit minerali de gang minerallerinden gravite ve manyetik ayırma teknikleri kullanılarak ayrılmaktadır (Hedrick vd., 1997). Monazit ve bastnazit minerallerinden başka ksenotim gibi NTE minerallerinin flotasyonu üzerine daha az çalışma yapılmıştır (Cheng vd., 1993 ve 1994; Cheng, 2000). Ksenotim, daha çok monazit zenginleştirme prosesinin yan ürünü olarak kazanılmaktadır.

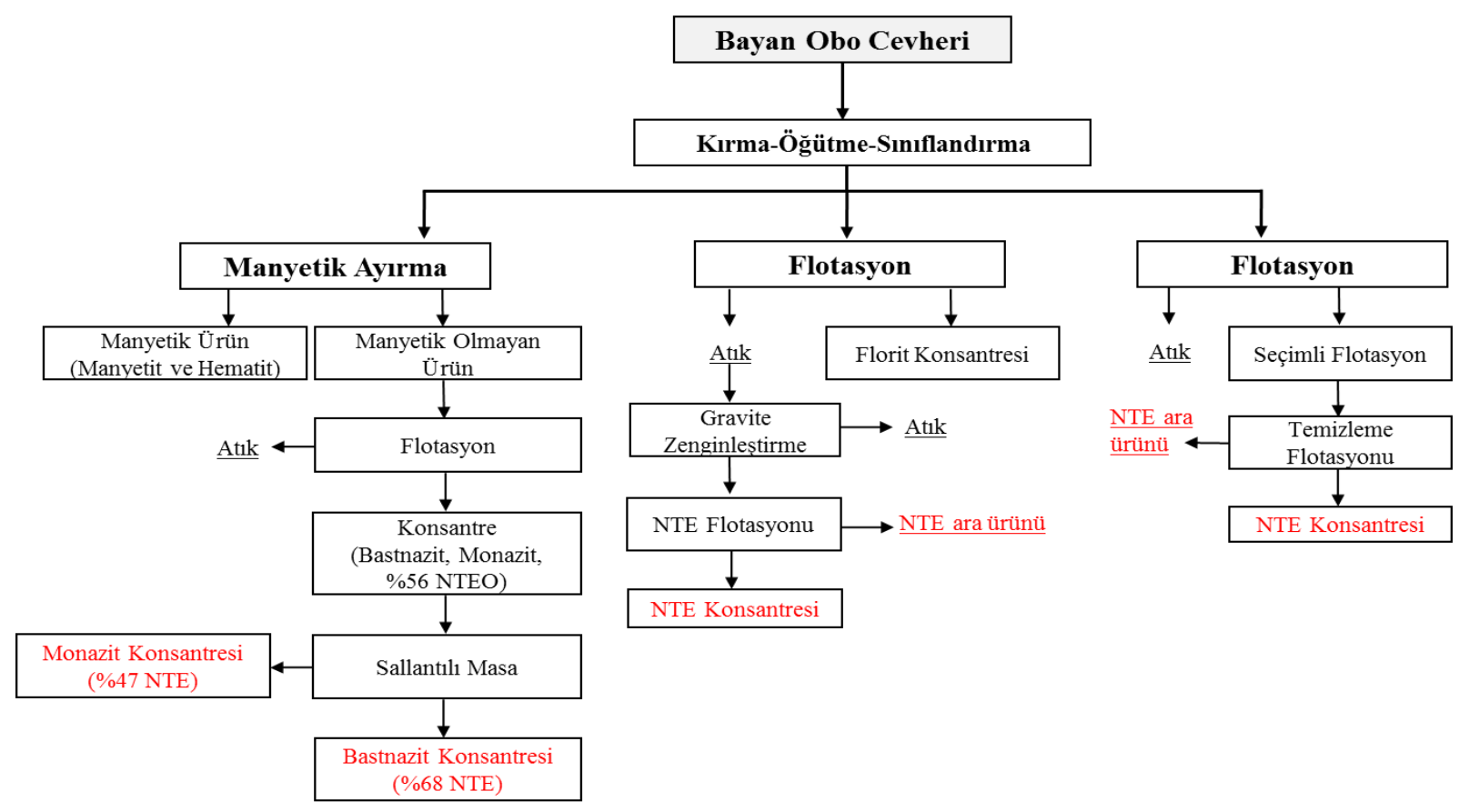

Şekil 1. Bastnazit ve monazit içeren Bayan Obo cevherinden fiziksel zenginleştirme yöntemleriyle NTE'lerin kazanımı (NTE: Nadir toprak elementi) (Anderson, 1986; Li vd., 1988; Houot vd., 1991).

\subsubsection{Hidrometalurjik yöntemler}

Cevherlerden ya da fiziksel ayırma yöntemleriyle üretilmiş konsantrelerden (\%60-70 NTE), NTE uygun hidrometalurjik yöntemlerle kazanılmaktadır. NTE'lerin liçinde asidik $\left(\mathrm{H}_{2} \mathrm{SO}_{4}\right.$, $\left.\mathrm{HNO}_{3}, \mathrm{HCI}\right)$ ya da alkali $(\mathrm{NaOH})$ reaktif sistemleri kullanılmakta ve liç sonrasında üretilen yüklü liç çözeltilerinden NTE'nin kazanımında çöktürme/solvent ekstraksiyon/iyon değişimi gibi yöntemleri içeren saflaştırma ve kazanım yöntemleri kullanılmaktadır (Akkurt vd., 1993; Kumar vd., 2014). Monazitten NTE'lerin ve toryumun kazanımında sülfürik asit liçi yaygın bir şekilde kullanılmaktadır (Eşitlik 1) (Şekil 2) (Krishnamurthy ve Gupta, 2016). Toryum ve NTE ya seçimli ya da beraber çözündürülerek

$$
\begin{aligned}
& 2 \mathrm{REPO}_{4}+3 \mathrm{H}_{2} \mathrm{SO}_{4} \rightarrow(\mathrm{RE})_{2}\left(\mathrm{SO}_{4}\right)_{3}+6 \mathrm{H}^{+}+2 \mathrm{PO}_{4}{ }^{3-} \\
& \mathrm{LnPO}_{4(\mathrm{k})}+3 \mathrm{HNO}_{3(\mathrm{~s})} \rightarrow \mathrm{Ln}^{3+}{ }_{(\mathrm{s})}+3 \mathrm{NO}^{-}{ }_{3(\mathrm{~s})}+\mathrm{H}_{3} \mathrm{PO}_{4(\mathrm{~s})} \\
& \mathrm{RE}\left(\mathrm{PO}_{4}\right)+3 \mathrm{NaOH} \rightarrow \mathrm{RE}(\mathrm{OH})_{3}+3 \mathrm{Na}^{+}+\mathrm{PO}^{3-}{ }_{4}
\end{aligned}
$$

kazanılmaktadır. Endüstriyel olarak kullanılan proseste, NTE içeren sülfatlı çökelekler elde edilmektedir. Sülfürik asit liçi sonrasında sülfat çözeltilerinden NTE'ler okzalat ile uygun $\mathrm{pH}$ 'da çöktürülürler. Nadir toprak elementlerinin birbirlerinden ayrılmasinda solvent ekstraksiyon yöntemi yaygın olarak kullanılmaktadır. Nitrik asit liç çözeltilerinden toryum, uranyum ve seryumun ayrılmasında tribütil fosfat (TBF) kullanılarak solvent ekstraksiyon yöntemiyle kazanılmaktadır. Nitrik asit liçi ile monazit içeren cevherlerden lantanın kazanımına yönelik çalışmalar da bulunmaktadır (Kuzmin vd., 2012) (Eşitlik 2). Alkali ortamda $(\mathrm{NaOH})$, monazitten NTE'nin çözünmesi Eşitlik 3'de verilmektedir (Kumar vd., 2014). 


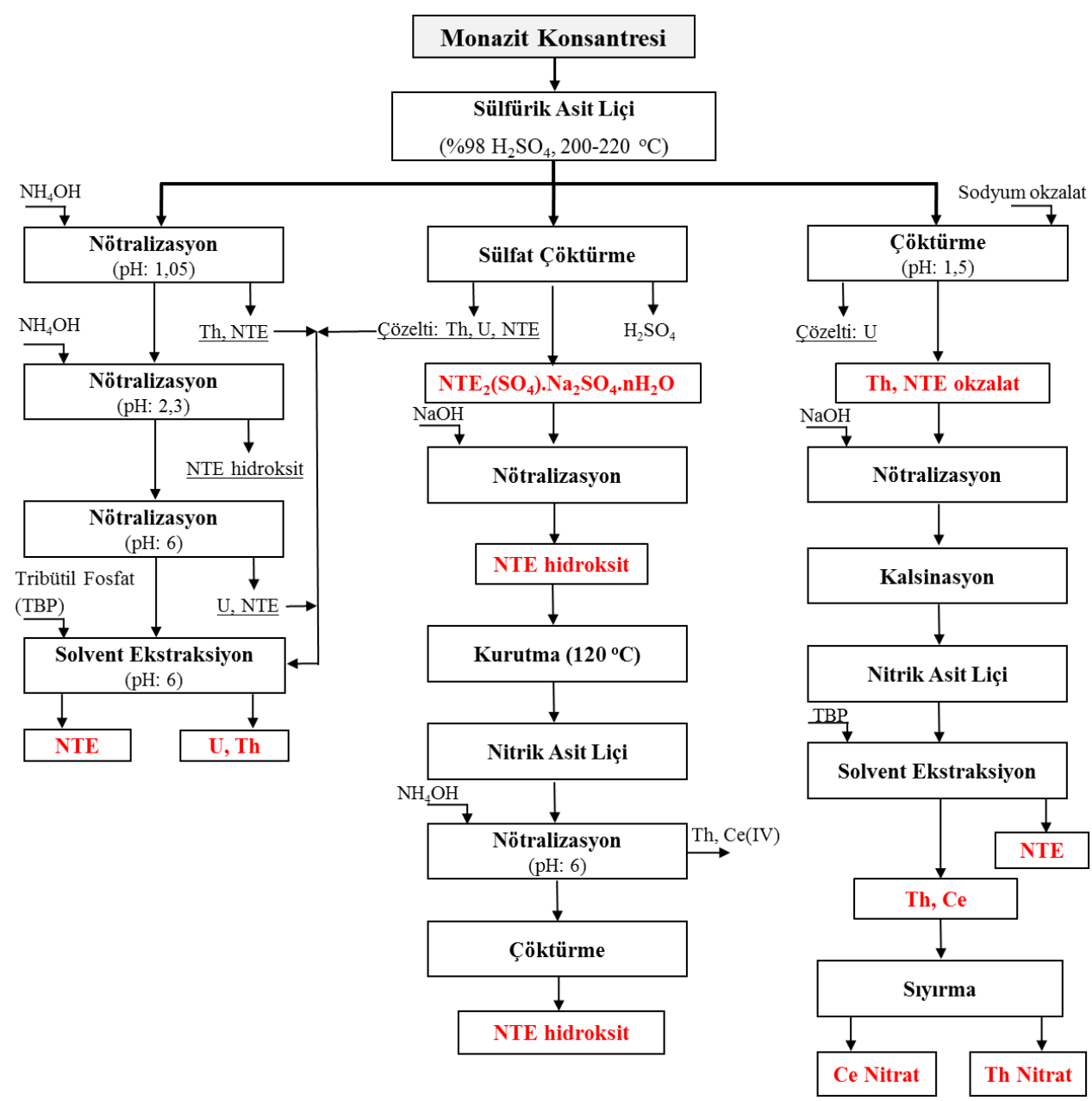

Şekil 2. Hidrometalurjik yöntemlerle monazit konsantresinden NTE'lerin kazanımı (Shaw vd., 1954; Krishnamurthy ve Gupta, 2016).

Sülfürik asit ile pişirme (baking) prosesi Bayan Obo (Çin) ve Mt. Weld (Avustralya) NTE yataklarından elde edilen konsantrelerden NTE üretimi için kullanılan yaygın bir prosestir (Topkaya ve Akkurt, 1999; Zhu vd., 2015; Sadri vd., 2017). Kul vd. (2008), Beylikahır (Eskişehir) bastnazit $\left(\mathrm{LaFCO}_{3}\right)$ konsantresinden, sülfürük asit ile pişirme sonrasında $\left(0,91 \mathrm{~kg} \mathrm{H}_{2} \mathrm{SO}_{4} /\right.$ konsantre $\left.\mathrm{kg}, 200^{\circ} \mathrm{C}\right)$ su liçi $\left(25^{\circ} \mathrm{C}, \mathrm{K} / \mathrm{S}=1: 4,2\right.$ sa., $\% 90 \mathrm{NTE}$

$$
\begin{aligned}
& 2 \mathrm{LaFCO}_{3}+3 \mathrm{H}_{2} \mathrm{SO}_{4} \rightarrow \mathrm{La}_{2}\left(\mathrm{SO}_{4}\right)_{3}+2 \mathrm{HF}+2 \mathrm{H}_{2} \mathrm{CO}_{3} \\
& \mathrm{La}_{2}\left(\mathrm{SO}_{4}\right)_{3}+\mathrm{Na}_{2} \mathrm{SO}_{4}+2 \mathrm{H}_{2} \mathrm{O} \rightarrow \mathrm{Na}_{2} \mathrm{SO}_{4} \cdot \mathrm{La}_{2}\left(\mathrm{SO}_{4}\right)_{3} \cdot 2 \mathrm{H}_{2} \mathrm{O} \\
& \mathrm{CaF}_{2}+\mathrm{H}_{2} \mathrm{SO}_{4} \rightarrow \mathrm{CaSO}_{4}+2 \mathrm{HF}
\end{aligned}
$$

verimi) ve sodyum sülfat çöktürme işlemleriyle ( 90 ${ }^{\circ} \mathrm{C}, \mathrm{Na}_{2} \mathrm{SO}_{4}$ stokiyemetrik oran1 1,25) NTE-sülfat bileşiği elde etmişlerdir (Eşitlik 4 ve 5). Sülfürik asit ile pişirme esnasında suda çözünebilir sülfatlı NTE bileşikleri $\left(\mathrm{La}\left(\mathrm{SO}_{4}\right)_{3}\right)$ oluşur. Cevherdeki kalsiyum florür $\left(\mathrm{CaF}_{2}\right)$ jipse $\left(\mathrm{CaSO}_{4}\right)$ dönüşür ve katı kısımda kalır (Eşitlik 6). Oluşan HF gazı yan ürün olarak kazanılabilmektedir. Prosesin akım şeması Şekil 3'de verilmektedir. 


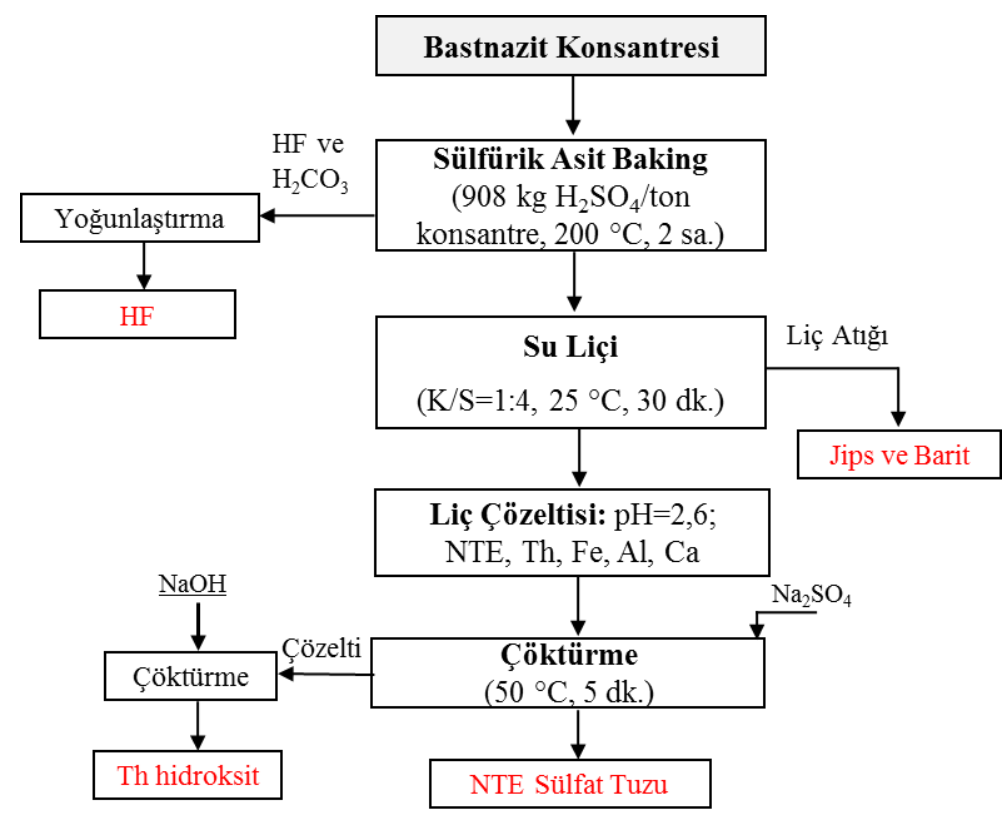

Şekil 3. Beylikahır (Eskişehir) bastnazit konsantresinden sülfürik asit ile pişirme ve su liçiyle NTE kazanımı (Kul vd., 2008).

Bastnazit cevheriyle ilgili olarak yapılan diğer bazı çalışmalarda, Kurşunoğlu vd. (2020), Kızılcaören (Eskişehir) bastnazit cevherinden direk asit liçiyle en yüksek lantanyum (La) ve seryum (Ce) kazanımlarının nitrik asit kullanarak $(>\% 85 \mathrm{La}$ ve Ce) elde edilebileceğini göstermişlerdir. Kurşun vd. (2017), aynı bölgedeki cevherlerden nitrik asit liçiyle (\%35 katı oranı, $400 \mathrm{~kg} /$ ton $\mathrm{HNO}_{3}, 120 \mathrm{dk}$. liç süresi ve $\left.60{ }^{\circ} \mathrm{C}\right) \% 82,35 \mathrm{Ce}, \% 77,43 \mathrm{Nd}$ ve \%70,21 La kazanımları elde etmişlerdir.

\section{2. İkincil kaynaklardan nadir toprak elementlerinin kazanımı}

\subsubsection{Nd-Fe-B miknatıslar}

NTE içeren en yaygın mıknatıslar neodimyumdemir-bor (NdFeB) mıknatıslarıdır. Kobalt gibi stratejik öneme sahip elementlerin fiyatlarındaki artış, kobalt içermeyen kalıcı mıknatısların üretilmesine sebep olmuştur. Bu gelişmelere bağl1 olarak 1983 yilında, geleneksel toz metalurjisi ve ergitme yöntemleri kullanılarak Nd-Fe-B esasl1 kalıcı mıknatıslar üretilmiştir (Sagava vd., 1984; Croat vd., 1984; Icin, 2016). Üretim yöntemleri arasında en yaygın yöntem olan toz metalurjisi yöntemlerini içeren sinterleme yöntemidir. Sinterlenmiş mıknatısların manyetik özellikleri $\mathrm{Nd}_{2} \mathrm{Fe}_{14} \mathrm{~B}$ fazından dolayı yüksektir. Bu fazın birim hacimde ürettiği enerji miktarı yaklaşık olarak 512 $\mathrm{kJ} / \mathrm{m}^{3}$ 'tür. $\mathrm{NdFeB}$ mıknatısların yüksek kalıcı mıknatıslığa sahip olmalarının en önemli nedeni, mıknatısın bileşimini oluşturan NTE (Nd) ve geçiş metali $(\mathrm{Fe})$ arasında güçlü ferromanyetik bir etkileşimin gerçekleşmesidir (Icin, 2016).
Ferromanyetik özellik göstermeyen üçüncü katk1 elementi olan bor, oluşan manyetik akının azalmasını engellemek amacıyla küçük miktarlarda ikili alaşım sistemine eklenmektedir $(\% 72 \mathrm{Fe}, \% 27 \mathrm{Nd}$ ve \%1 B). NdFeB kalıc1 mıknatıslar, \%31-32 oranında NTE içermektedir. Temelde $\mathrm{Nd} / \mathrm{Fe} / \mathrm{B}$ içeriğinin dişında; \%21-31 oranında $\mathrm{Nd}+\mathrm{Pr}$; \%0-10 arasında Dy (Elektrikli otomobil motorlarında); az oranda $\mathrm{Gd}$ ve $\mathrm{Tb}$; koruma kaplamasında $\mathrm{Ni}$ ve $\mathrm{Cu}$ kullanılmaktadır. İhtiyaç duyulan alanla ilgili olarak mıknatısın bazı fiziksel ve manyetik özelliklerini değiştirmek amaciyla da $\mathrm{Dy}, \mathrm{Tb}, \mathrm{Gd}, \mathrm{Nb}, \mathrm{Co}, \mathrm{Cu}, \mathrm{Ga}$ ve $\mathrm{Al}$ kullanılmaktadır. Bu mıknatıslar \%5'e kadar kobalt içerebilirler (Binnemans vd., 2013; Yang vd., 2017). Bu açıdan bakıldığında atık mıknatıslar neodimyum başta olmak üzere önemli bir nadir toprak elementi kaynağıdır.

Dünya yıllık NTE üretimi 2005-2015 yılları arasında yaklaşık 120.000 ton (oksit formu) olarak bildirilmiştir. 2006 ve 2009 yıllarında NTE üretimi 137.000 ton'a yükselmiştir. Üretilen NTE'nin yaklaşık 26.000 tonu yılda NdFeB mıknatıslarının üretiminde kullanılmaktadır (USGS, 2016). 2008 yılında, yaklaşık 26.300 ton (oksit formu) NTE (Nd, Pr, Dy, Gd ve Tb) miknatıs üretiminde kullanılmıştır (Yang vd., 2017). Toplam kullanılan neodimyumun \%76's1 (23.900 ton; 18.164 ton), praseodimun \%70'i (8740 ton; 6.118 ton) gadolinyumun \%69'u (762 ton; 525 ton) ve disporsiyumun \%100'ü (1310 ton) miknatıs üretiminde kullanılmıştır. Japonya ve Çin ana NTE ve mıknatıs üreten ülke olup NTE'nin \%80'ini Çin üretmektedir. 
Neodimyum, yaygın bir şekilde Nd-Fe-B mıknatıslarının üretiminde kullanılır. NTE içeren bu mıknatısların 20'den fazla farklı uygulaması tanımlanmıştır. $\mathrm{Bu}$ mıknatıslar, cevher zenginleştirmede kullanılan manyetik ayırıcılarda, bilgisayar sabit disklerinde, elektrikli ev aletlerinde, elektronik cihazlarda (mikrofon, kulaklık vb.), hibrit ve elektrikli araç motorlarında ve rüzgâr türbinlerinde yaygın bir şekilde kullanılmaktadır (Tablo 5). Kullanılan ekipmana/cihaza bağlı olarak Nd-Fe-B mıknatıslarının boyutları küçük ev aletlerinde $<1$ gr, hibrit ve elektrikli araçlarda yaklaşık 1 kg'a kadar çıkmaktadır. Rüzgar türbinlerinin jeneratörlerinde $\quad 1000-2000 \mathrm{~kg}$ büyüklüğ̈nde mıknatıslar kullanılmaktadır (Yang vd., 2017).

Tablo 5. NdFeB mıknatısların kullanım alanları (Yang vd., 2017).

\begin{tabular}{lcc}
\hline Kullanıldı̆̆ı Sektör & Birim Başına Kütle & Toplam Kullanım, Ton \\
\hline Bilgisayarlar (Sabit diskler vb.) & $10-20 \mathrm{~g}$ & 7.500 \\
Elektrikli-Elektronik Eşyalar (Hoparlörler, klimalar vb.) & değişken & $>8.500$ \\
Rüzgâr Türbinleri & $400 \mathrm{~kg} / \mathrm{MW}$ & 8.500 \\
Araçlar & & \\
1. Otomobiller (Küȩük motorları ve sensörleri vb.) & $250 \mathrm{~g}$ & 22.000 \\
2. Elektrikli araç motorları (HEV, PEHHV ve EV) & $1,25 \mathrm{~kg}$ & $>7.000$ \\
3. Elektrikli bisikletler (Elektrik motorları) & $300-350 \mathrm{~g}$ & 6.000 \\
Toplam & & 51.000 \\
\hline
\end{tabular}

Kalıcı mıknatısların gelişimine bağlı olarak bu mıknatıslar cevher zenginleştirme ekipmanlarında da kullanılmaya başlanmıştır (Hassoy, 2007) (Şekil 4). Nd-Fe-B alaşımlı kalıcı mıknatısların manyetik ayırıcılarda kullanılmasıyla zayıf paramanyetik minerallerin (mika, hornblend vb.) ayrilması ve endüstriyel hammaddelerin (feldispat, manyezit vb.) zenginleştirilmesi mümkün olmuştur. Son 20 y1l içerisinde, yüksek manyetik alan şiddetine sahip olan Nd-Fe-B mıknatıslarının kullanıldığı tambur ve rulo tipi ayırıcılarda, NTE içeren cevherlerin zenginleştirilmesi, zayıf manyetik minerallerin ve metalik olmayan cevherlerin ayrılması ve cüruf ya da şlamların değerlendirilmesi amacıyla geliştirilmiş ve yaygın bir şekilde uygulama alanı bulmuştur (Straka ve Žežulka, 2019). Rulo tipi manyetik ayırıcıda kullanılan manyetik rulolar, kalınlıkları 3-12 mm arasında değişen Nd-Fe-B alaşımlı kalıcı mıknatıs diskleri içerir. Bu rulo, mıknatıs diskler ile beraber yumuşak çelikten yapılmış diskler arasında dilimler şeklinde birleştirilmesiyle yapılırlar. Bu dizilim sayesinde 1,7 Tesla civarında bir manyetik alan şiddeti oluşturulmaktadır. Manyetik tambur ayırıcılarda, ferrit mıknatıs blokları ya da küçük Nd-Fe-B blokları, dönen tambur içerisine yerleştirilmiş çelik segmentin yüzeyine monte edilirler (Svoboda ve Fujita, 2003; Svoboda, 2004). Manyetik ayırıcılar dışında, manyetik filtreler, yüksek alan şiddetine sahip mıknatısları içeren ve sıvı (ya da yă̆) içerisindeki mikron boyutundaki manyetik tanelerin uzaklaştırılmasında kullanılan ekipmanlardır. Cevher hazırlama proseslerinde kullanılan bu ekipmanlarda da Nd-Fe-B mıknatısların kullanımı yaygındır (Žežulka vd., 2005; Straka ve Žežulka, 2019).
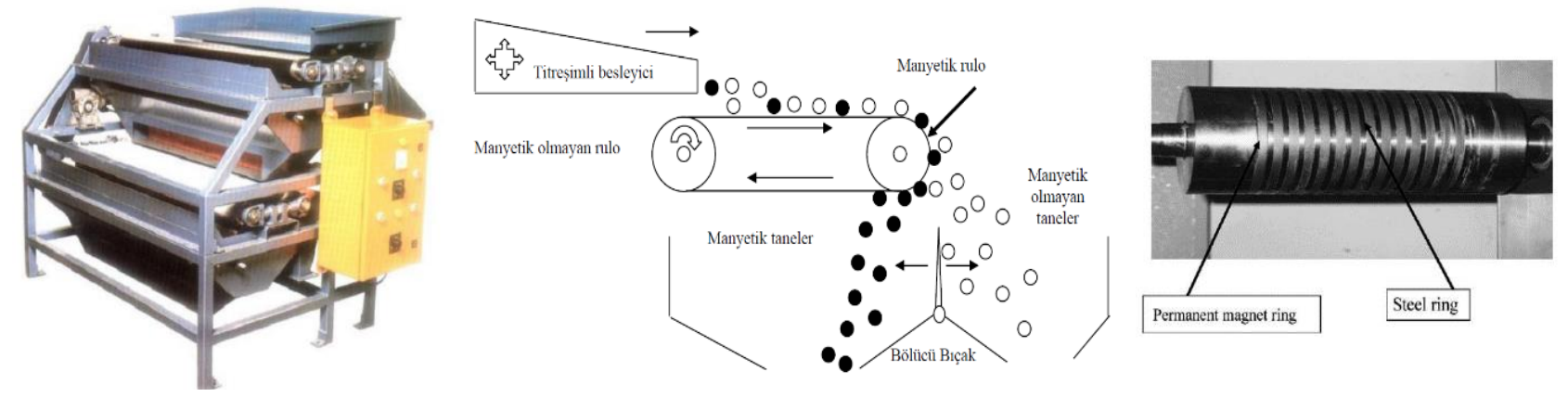

Şekil 4. Endüstriyel ölçekli rulo tipi kuru manyetik ayırıcı (sol) (Bateman Permroll), temsili görünümü (orta) (Hassoy, 2007) ve kalıcı rulo mıknatısın görünümü (sağ) (Straka ve Žežulka, 2019).

Modern teknolojilerde kullanımı hızla artan ve çok farklı uygulama alanları bulunan Nd-Fe-B mıknatıslarının üretiminde kullanılan NTE'nin geri dönüşümü günümüzde oldukça önemlidir. Hizmet süresi ve üretim süreci düşünüldüğünde bilgisayar sabit diskleri, rüzgâr türbinleri ve otomotiv endüstrisi $\mathrm{Nd}-\mathrm{Fe}-\mathrm{B}$ mıknatıslarının geri dönüşüm potansiyeli olan uygulamalar olarak 
düşünülmektedir (Rademaker vd., 2013). Bu değerlendirmeye manyetik ayırıcı mıknatısları üretim atıkları katılmamıştır. Nd-Fe-B mıknatıslarından nadir toprak elementlerinin geri kazanımı amacıyla yapılan araştırmalar çoğunlukla bilgisayar sabit disklerindeki mıknatıslar üzerine yoğunlaşmaktadır.

Nd-Fe-B mıknatıslarının üretildiği tarihten itibaren 2007 y1lına kadar toplam 97.000 ton Nd, Pr, Dy ve $\mathrm{Tb}(62.6 \mathrm{kt} \mathrm{Nd}, 15.7 \mathrm{kt}$ Pr, $15.7 \mathrm{kt}$ Dy ve $3.1 \mathrm{kt} \mathrm{Tb})$ gibi NTE'nin kullanıldığı rapor edilmiştir (Du ve Graedel, 2011). Bu miktar, cevherlerden üretilen miktarın yaklaşık 4 katına eşittir. Yapılan modellemelere göre, 2050 y1lında $\mathrm{Nd}$ ve Dy'ye olan taleplerin karşılanamayacağı ve geri dönüşüm olmaksızın 2050 yılında arz-talep arasındaki boşluğun kapanmasının mümkün olamayacağı tahmin edilmektedir. Bununla birlikte, 2100 yılında geri dönüşümden sağlanan üretim miktarının ihtiyaç duyulacak talebin \%50'sini karş1layabileceği öngörülmektedir (Habib ve Wenzel, 2014). Bu açıdan bakıldığında, gelecek 10-15 y1l içerisinde ömrünü tamamlamış Nd-Fe-B mıknatıslarından NTE'nin geri kazanımı oldukça önemli olacaktır.

Bununla birlikte, miknatıs üretim esnasında sinterleme, manyetizasyon ve istenen şekli vermek için kesme ve öğütme işlemlerinde kullanılan miknatısların \%20-30'u atık durumuna gelmektedir (1500-2500 t/y1l) (Rabatho vd., 2013). Türkiye'de Nd-Fe-B mıknatısları kullanarak manyetik ayırıcı üreten yaklaşık 5 firma bulunmaktadır. Kullanılan mıknatıslardan yaklaşık $0,5 \mathrm{~kg} / 100 \mathrm{~kg}$ atık oluştuğu ve üretim esnasında yaklaşık 2,5 ton/yıl Nd-Fe-B mıknatıs atık olarak hurdaya verildiği bildirilmiştir (Tumbaz, 2019).

NdFeB mıknatıs atıklarından NTE'nin geri kazanımında ön işlemlerin (hidrojen dekrepitasyon gibi) yan1 sira hidrometalurjik ve pirometalurjik yöntemler kullanılmaktadır (Şekil 5) (Yang vd., 2017). Pirometalurjik yöntemlerin yüksek enerji gereksinimi ve düşük seçimliliğe sahip olması gibi dezavantajları bulunmaktadır. Bununla birlikte, hidrometalurjik yöntemler özellikle düşük tenörlü malzemeler ve küçük çaplı uygulamalar için uygun yöntemler olup düşük enerji tüketimine ve düşük gaz emisyonuna sahip olmaları nedeniyle de daha düşük çevresel etkilere sahiptirler. Ayrıca, çevresel etkisi daha düşük organik reaktiflerin kullanılması hidrometalurjik yöntemleri NTE'nin kazanımı için daha da uygun hale getirmektedir (Behera ve Parhi, 2016; Reisdörfera vd., 2019). Günümüzde NdFeB mıknatısların ve nadir toprak elementlerinin geri kazanımına yönelik ticari bir uygulama tanımlanmamıştır.

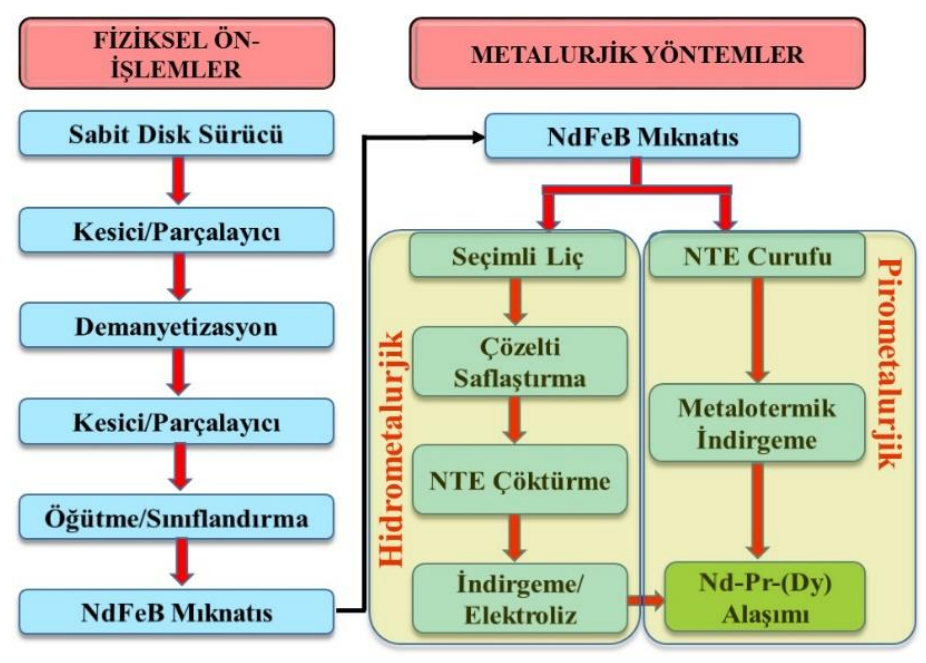

Şekil 5. Bilgisayar sabit disklerinden NTE’nin geri kazanımını gösteren akım şeması (Yang vd., 2017).

Kalıcı miknatıslardan nadir toprak elementlerinin (Nd, Pr, Dy) geri kazanılmasında hidrometalurjik yöntemler yaygın bir şekilde kullanılmaktadır (Binnemans vd., 2013). Sülfürik asit, nitrik asit ve hidroklorik asit gibi inorganik asitlerin kullanıldığ liç yöntemleri uygulanmaktadır (Yang vd., 2017). İnorganik asitlerden başka malik asit, sitrik asit, okzalik asit ve asetik asit gibi organik asitlerin kullanıldığı çalışmalarda mevcuttur (Bandara vd.,
2016; Reisdörfera vd., 2019; Erust vd., 2019). Liç yöntemi olarak ya konsantre asit liçi (Lyman ve Palmer, 1993; Rabatho vd., 2012) ya da oksitleyici kavurma-seçimli asit liçi (Hoogerstraete vd., 2014) yöntemleri araştırılmıştır. Maliyetinin daha düşük olması ve sülfat çözeltilerinden çöktürme işleminin nispeten kolay olması nedeniyle genellikle sülfürik asit liçi kullanılmaktadır (Eşitlik 7) (Lyman ve Palmer, 1993; Hua, 2016; Parthasarathy ve 
Bulbule, 2019). Sülfürik asit liçinden başka HCI asit liçi de mıknatıslardan neodimyum kazanımı için irdelenmiştir (Bandara vd., 2016; Erust vd., 2019). Konsantre asit liçinde asit tüketimi yüksek olup demir de çözündüğü için seçimli bir yöntem değildir. Yüksek miktarda çözünen demirin çözeltiden uygun bir şekilde uzaklaştırılması (jarosit çöktürme) gerekmektedir (Abrahami vd., 2015; Bandara vd., 2016). Bu nedenle liç sonrasında seçimli çöktürme işlemi gerektirmektedir. Çözünen bor, çinko borat hidrat olarak kazanilabilmektedir (Lyman ve Palmer, 1993). Yüklü liç çözeltisinden neodimyum florür (HF ile) ya da okzalat olarak çöktürülebilir. Bunların yanı sira sodyum hidroksit ya da amonyum sülfat ile sülfat tuzu olarak da çöktürülebilir (Lyman ve Palmer, 1993; Hua,
2016). Elde edilen neodimyum-sülfat $\left(\mathrm{Nd}_{2}\left(\mathrm{SO}_{4}\right)_{3} \cdot \mathrm{Na}_{2} \mathrm{SO}_{4} \cdot 6 \mathrm{H}_{2} \mathrm{O}\right)$ çökeleği hidrojen florür (HF) ya da okzalik asit ile beraber sirasiyla $\mathrm{NdF}_{3}$ ya da $\mathrm{Nd}_{2} \mathrm{O}_{3}$ 'e dönüştürülmektedir (Eşitlik 8) (Hoogerstraete vd., 2014). Ancak bu proseslerden elde edilen florit çökeleği, oluşan jelatinimsi yapısından dolayı filtrasyonu zorlaştırmaktadır. Ayrıca okzalat çöktürme maliyetli bir işlem olup neodimyumu oksit formunda elde etmek için okzalat çökeleğinin tekrar kavrulması gerekmektedir (Lyman ve Palmer, 1993). Ayrica çözeltide bulunan demir, okzalat çöktürmesini olumsuz etkilemektedir (Lyman ve Palmer, 1993). Çözelti saflaştırma (jarosit çöktürme) işleminden sonra çöktürme işleminden farklı olarak NTE, solvent ekstraksiyon yöntemiyle de kazanılabilmektedir (Erust vd., 2019).

$\mathrm{Nd}_{2} \mathrm{Fe}_{14} \mathrm{~B}+17 \mathrm{H}_{2} \mathrm{SO}_{4} \rightarrow \mathrm{Nd}_{2}\left(\mathrm{SO}_{4}\right)_{3}+14 \mathrm{FeSO}_{4}+17 \mathrm{H}_{2}+\mathrm{B}$

$\mathrm{NTE}_{2}\left(\mathrm{SO}_{4}\right)_{3}+3 \mathrm{C}_{2} \mathrm{H}_{2} \mathrm{O}_{4} \rightarrow \mathrm{NTE}_{2}\left(\mathrm{C}_{2} \mathrm{O}_{4}\right)_{3}+3 \mathrm{H}_{2} \mathrm{SO}_{4}$

Liç işleminde seçimliliği sağlamak için öncesinde neodimyumu oksitlemek amaciyla seçimli oksidasyon $\left(500{ }^{\circ} \mathrm{C}\right.$ ve $\left.950{ }^{\circ} \mathrm{C}\right)$ işlemi önerilmiştir (Eşitlik 9) (Onal vd., 2015). Kavurma işleminde oluşan demir ve kobalt oksitlerin çözünme kinetiğinin NTE oksitlerinkinden daha yavaş olması nedeniyle liç esnasında seçimlilik sağlanmakta ve demir katıda (hematit gibi) kalmaktadır (Eşitlik 10). Ancak oksidasyon sırasında $\mathrm{NdFeO}_{3}$ oluşumu neodimyumun çözünmesini engelleyebilmektedir (Eşitlik 11) (Onal vd., 2015). Prosesin bir diğer dezavantaj1,

$\mathrm{Nd}_{2} \mathrm{Fe}_{14} \mathrm{~B}+{ }^{3} / 2 \mathrm{O}_{2(\mathrm{~g})} \rightarrow \mathrm{Nd}_{2} \mathrm{O}_{3}+14 \mathrm{Fe}+\mathrm{B}$

$2 \mathrm{Fe}+{ }^{3} / 2 \mathrm{O}_{2(\mathrm{~g})} \rightarrow \mathrm{Fe}_{2} \mathrm{O}_{3}$

$\mathrm{Fe}_{2} \mathrm{O}_{3}+\mathrm{Nd}_{2} \mathrm{O}_{3} \rightarrow 2 \mathrm{NdFeO}_{3}$

NTE'nin seçimli olarak çözündürülmesinde sülfatlayıcı kavurma ve liç yöntemi de araştırılmıştır (Borra vd., 2016). Bu proseste önce sülfatlama aşamasında malzeme ile konsantre sülfürik asit karışımı kurutulur. $\mathrm{Bu}$ aşamada malzemedeki oksitlerin çoğu sülfatlı bileşiklerine dönüştürülür. Kavurma işleminde $\left(600-800{ }^{\circ} \mathrm{C}\right)$ sülfürik asit ve metaller arasinda reaksiyon sonucunda NTE, sülfatlı bileşiklerine dönüştürülür (Eşitlik 12) (Onal vd., 2015). Sonrasında bu sülfatlı bileşikler su liçi veya hafif asidik ortamda (pH:5)

$\mathrm{xM}+\mathrm{yH}_{2} \mathrm{SO}_{4}(\mathrm{aq}) \rightarrow \mathrm{Mx}\left(\mathrm{SO}_{4}\right) \mathrm{y}(\mathrm{aq})+\mathrm{yH}_{2}(\mathrm{~g})$

$\mathrm{Fe}_{2}\left(\mathrm{SO}_{4}\right)_{3} \rightarrow \mathrm{Fe}_{2} \mathrm{O}_{3}+3 \mathrm{SO}_{3}$
(NTE: Nadir toprak elementi)

kavurma esnasında sülfat bileşiklerinin endotermik termal bozunma reaksiyonları için nispeten yüksek sıcaklıklara $\left(\geq 800^{\circ} \mathrm{C}\right)$ ihtiyaç duyulması nedeniyle enerji sarfiyatının yüksek olmasıdır (Onal vd., 2017; Zhang vd., 2018). Bununla birlikte neodimyum (III) sülfat için termal bozunma sicaklıkları da yüksektir $\left(800-1027^{\circ} \mathrm{C}\right)$ (Onal vd., 2015; Borra vd., 2016). Ayrica zararlı gaz $\left(\mathrm{SO}_{2}\right)$ emisyonu da bu yaklaşımın diğer bir dezavantajıdır.

çözündürülmektedirler. Bununla birlikte, 600-700 ${ }^{\circ} \mathrm{C}$ 'de $\mathrm{Fe}$ (III) sülfat gibi düşük termal kararlılığa sahip sülfatlar suda çözünmeyen oksitlerine dönüşürler (Eşitlik 13) (Borra vd., 2016). Asit rejenerasyonunun mümkün olması nedeniyle asit tüketimleri daha düşüktür. Ayrıca direkt liçe göre daha küçük hacimlerde ve yaklaşık nötr pH'a sahip bir atık suyun oluşumu avantajına sahiptir. Ancak proses esnasında doğrudan liç işlemine kıyasla öncesinde kavurma işleminin uygulanması gerekmektedir (Borra vd., 2016).

(M: Metal) 
Onal vd. (2015), otomotiv endüstrisi mıknatıs atıklarından $(<40 \mu$ m'a ögütülmüsş $)$ sülfatlayıcı kavurma $\left(14,5 \mathrm{M} \mathrm{H}_{2} \mathrm{SO}_{4}, 650-850{ }^{\circ} \mathrm{C}, 1\right.$ saat) sonrasında su liçiyle NTE'nin (Nd, Dy, Pr, Gd, Tb ve $\mathrm{Eu})$ \%95-100 kazanma verimiyle elde etmişlerdir. Farklı asit-katı karışımı oranlarında hazırlanan numuneler kavrulduktan sonra kalsinenin su liçinde $\left(0,02 \mathrm{~g} / \mathrm{mL}, 1\right.$ saat, $\left.25^{\circ} \mathrm{C}\right)$ NTE kazanılırken demir, kalsinede hematit olarak kalmaktadır.

Sülfürik asitin kullanıldığı sülfatlayıcı kavurma prosesinin yüksek sicaklıklarda gerçekleşmesi $\left(\geq 800{ }^{\circ} \mathrm{C}\right)$ ve sülfürik asidin düşük sıcaklıklarda $\left(337{ }^{\circ} \mathrm{C}\right)$ buharlaşması gibi dezavantajına karşın amonyum sülfat ortamında kavurma işlemi daha düşük sicaklıklarda $\quad\left(300-400 \quad{ }^{\circ} \mathrm{C}\right)$ gerçekleştirilebilmektedir (Zhang vd., 2018). Ergitme $\left(>1600{ }^{\circ} \mathrm{C}\right)$, sülfatlayıcı kavurma $(450$ $\left.1000{ }^{\circ} \mathrm{C}\right)$, indirgeyici kavurma $\left(>800{ }^{\circ} \mathrm{C}\right)$, klorlayıcı kavurma $\left(600-1000{ }^{\circ} \mathrm{C}\right)$ gibi diğer kavurma işlemlerine kıyasla amonyum sülfat kavurma-liç prosesi daha düşük enerji tüketimlerine sahiptir (Li vd., 2017). Ayrica proseste kullanılan amonyumun geri kazanılmasıly, reaktif tüketimleri ve zararlı çevresel etkiler azaltılabilmektedir. Amonyum sülfat kavurma ve su liçi prosesinin, düşük maliyetli, yüksek ekstraksiyon oranı ve yüksek seçimliliğe sahip olan ve düşük tenörlü kompleks cevherlerin zenginleştirmesinde kullanılması mümkün olan bir yöntem olduğu ileri sürülmüştür (Li vd., 2017).

\subsubsection{Nikel-metal hidrür (NiMH) piller}

Hidrojenin metal hidrür formunda depolanması ve taşınabilir elektronik cihazlarda kullanılması amacıyla kurşun-asit, nikel-kadmiyum, nikel-metal hidrür ve lityum-iyon gibi şarj edilebilir piller geliştirilmektedir. Hidrojen depolama özelliklerinden dolayı NTE'ni içeren alaşımlar şarj edilebilir nikel-metal hidrür pillerde kullanılmaktadır. Örneğin $\mathrm{LaNi}_{5}$ önemli miktarda hidrojen gazı depolama özelliğine sahiptir. $\mathrm{LaNi}_{5} \mathrm{H}_{6}$ ' deki hidrojen yoğunluğu sivi hidrojenden çok daha yüksektir (Binnemas vd., 2013). Saf lantan fiyatının yüksek olması nedeniyle onun yerine hafif NTE'ni (La, Ce, Pr, Nd) içeren bir alaşım kullanılır. NiMH pili, negatif elektrot olarak metal hidrür, pozitif elektrot olarak $\mathrm{Ni}(\mathrm{OH})_{2}$ ve alkali elektrolitten $(\mathrm{KOH})$ oluşmaktadır.

Nikel-metal hidrür (NiMH) piller \%36-42 Ni, \%34 kobalt ve \%8-10 La, Ce, Pr ve Nd içeren bir alaşım içermektedirler. Bu pillerden nikel, kobalt ve NTE kazanımına yönelik çalışmalar yapılmaktadır (Zhang vd., 1998 ve 1999). Lyman ve Palmer (1995), NiMH at1k pillerinden HCI, $\mathrm{H}_{2} \mathrm{SO}_{4}$ ve $\mathrm{HNO}_{3}$ asit liçiyle NTE'ni çözündürmüşler ve en iyi sonuç $4 \mathrm{M}$ HCI asit liçinde elde edilmiştir. Çözündürülen NTE'ler klorür çözeltisine fosforik asit ilave edilerek fosfat olarak çöktürmüşlerdir. Şekil 6a'da sülfürik asit liçi sonrasında $\mathrm{Na}_{2} \mathrm{SO}_{4}$ ile çöktürme ve solvent ekstraksiyon yöntemleriyle metallerin ( $\mathrm{Ni}, \mathrm{Co}$ gibi) ve NTE'nin kazanımını gösteren akım şeması verilmektedir (Yoshida vd., 1995; Binnemas vd., 2013).

\subsubsection{Attk floresan lambalar}

Floresan lambalar (FLs) içerisindeki fosforesan malzeme Y, Eu ve Tb gibi NTE'ni içermektedir ve önemli bir ikincil kaynak konumundadırlar (Rabah, 2008; Binnemans vd., 2013). Atık fosforesan malzemelerden $\mathrm{H}_{2} \mathrm{SO}_{4}, \mathrm{HCI}, \mathrm{HNO}_{3}, \mathrm{NaOH}$ ve $\mathrm{NH}_{3}$ gibi asit ve baz liçi ile NTE'lerin kazanımına yönelik çalışmalar bulunmaktadır (Tan vd., 2015; De Michelis vd., 2011). Floresan atıklarından Y ve Eu'nun kazanımına yönelik önerilen bir akım şeması Şekil 6b'de verilmektedir (Takahashi vd., 2001). Yapılan çalışmada sülfürik asit (1,5 M) liçi sonrasında \%92 Y ve \%98 Eu çözündürülmüştür. Çözeltiden çöktürme sonrasında \%98 saflıkta Y ve Eu içeren NT oksit elde edilmiştir.

\subsubsection{Diğer ikincil kaynaklar}

Floresan lambalar (FLs) dışında TV ya da bilgisayar monitörlerindeki katot tüpleri (CRT), cam parlatma tozları, petrol rafineri katalizörleri (FCC) ve optik camlar diğer NTE içeren ikincil kaynaklardır (Binnemans vd., 2013, Jha vd., 2016).

CRT içerisinde kullanılan fosforesan materyaller $Y$ ve Eu içermekte ve NTE kaynağı olarak değerlendirilmektedir (Menad, 1999). Resende ve Morais (2010) sülfürik asit liçiyle bilgisayar monitörlerindeki $\mathrm{Eu}$ ve Y'yi \%97 verimle kazanmışlardır. 16,5 g/L Y ve 0,55 g/L Eu içeren ve solvent ekstraksiyonla NTE'lerin kazanılabileceği bir liç çözeltisi (pH: 0,3) elde edilmiştir.

Cam parlatma tozları $\mathrm{CeO}_{2}$ içermektedir ve önemli bir NTE uygulama alanıdır. 2008 yılında yaklaşık 10.000 ton $\mathrm{CeO}_{2}$ parlatma tozu üretilmiştir (Xu ve Peng, 2009). Atık parlatma tozları içerisindeki NTE'ler $\mathrm{HNO}_{3}-\mathrm{H}_{2} \mathrm{O}_{2}$ asit karışımında çözündürüldükten sonra karbonatla çöktürülmektedir (Binnemans vd., 2013). 
Optik camlar (kamera ve mikroskop lensleri) \%40 oranında $\mathrm{La}_{2} \mathrm{O}_{3}$ ve ilave olarak $\mathrm{Y}_{2} \mathrm{O}_{3}$ ve $\mathrm{Gd}_{2} \mathrm{O}_{3}$ içermektedirler. Yılda 20.000 ton optik cam üretildiği ifade edilmektedir. Yılda yaklaşık 1.600 ton NTE oksitin geri kazanım potansiyeli bulunmaktadır. Atık borosilikat optik camlardan (\%43,12 $\mathrm{L}_{2} \mathrm{O}_{3}, \% 9,37 \mathrm{Y}_{2} \mathrm{O}_{3}, \% 4,6 \mathrm{Gd}_{2} \mathrm{O}_{3}$ ) NTE'ler önce konsantre sodyum hidroksit ile NTEhidroksitlere dönüştürdükten sonra sıcak HCI asit liçiyle $(6 \quad \mathrm{M}) \quad$ NTE-klorürler olarak çözündürülmektedir (Jiang vd., 2004 ve 2005).

Petrol kimya endüstrisinde kullanılan katalizörler (FCC) temel olarak La'nın yanında daha az oranda $\mathrm{Ce}, \mathrm{Pr}$ ve $\mathrm{Nd}$ olmak üzere \%3,5 oranında NTE içermektedirler. Dünya'da üretilen La'nın \%50'si bu alanda kullanılmaktadır. FCC'lerden NTE'lerin geri kazanımında asit içi uygulamaları bulunmaktadır (Jha vd, 2016).

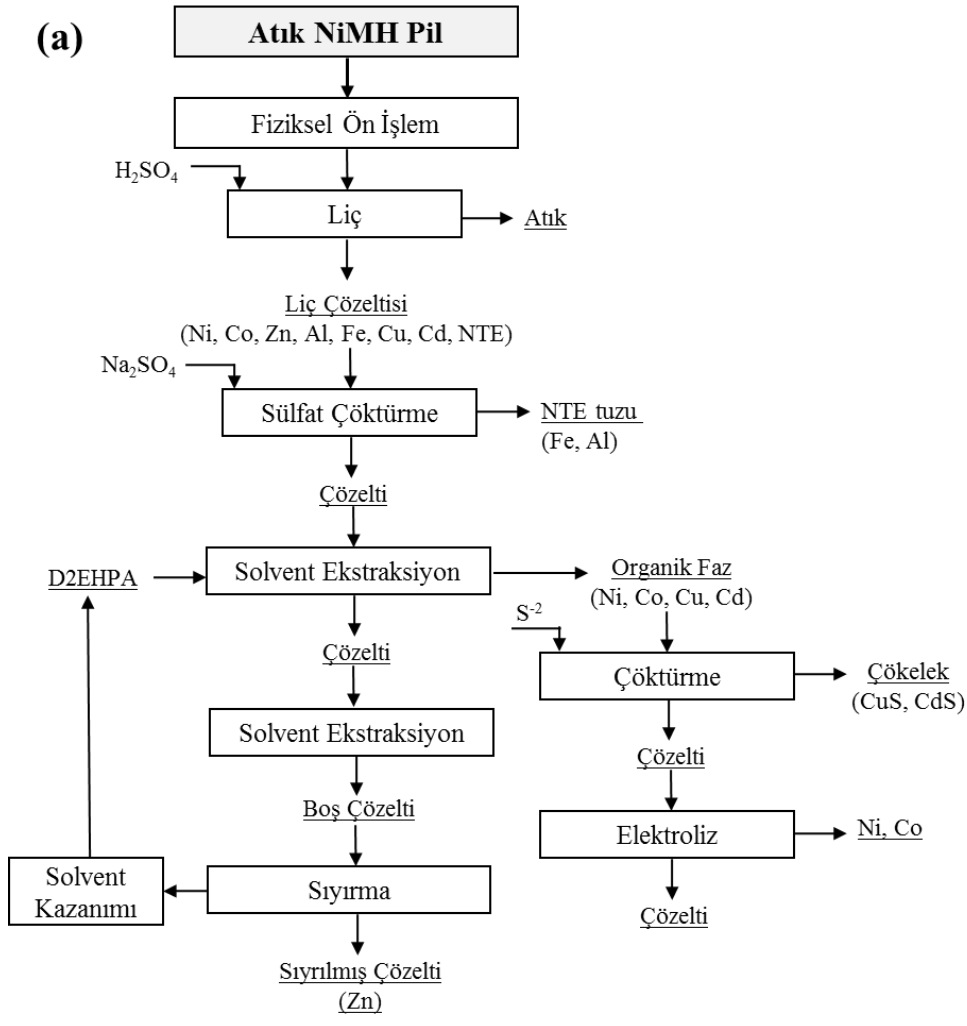

(b)

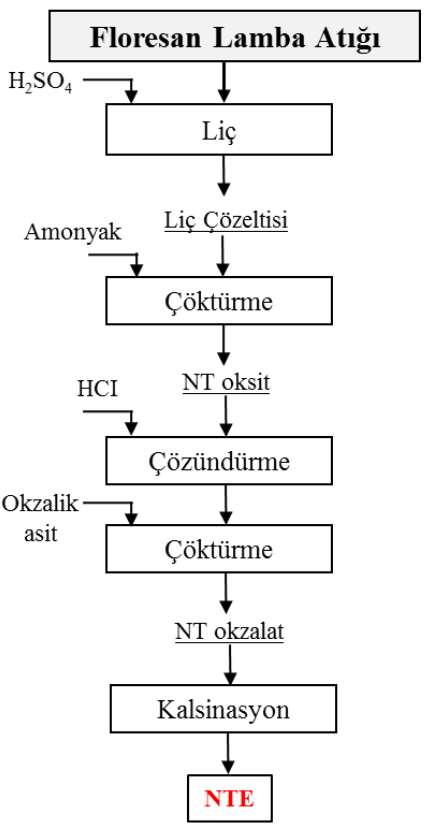

Şekil 6. a) Nikel-metal hidrür (NiMH) atık pillerinden metallerin geri kazanımını gösteren akım şeması (Yoshida vd., 1995); b) Floresan lamba atıklarından Y ve Eu'nun kazanımını gösteren akım şeması (Takahashi vd., 2001).

\section{Sonuçlar}

İleri teknolojik ürünlerin geliştirilmesine bağl1 olarak nadir toprak elementleri (NTE) gibi kritik hammaddelere olan ihtiyaç giderek artmaktadır. Bastnazit, monazit ve ksenotim gibi NTE içeren minerallerin zenginleştirilmesinde flotasyonla beraber gravite zenginleştirme (sallantılı masa, spiraller) yöntemleri kullanılmaktadır. Flotasyon konsantrelerinden NTE'nin kazanımında sülfürik asidin yaygın bir şekilde kullanıldığı hidrometalurjik yöntemler sonrası çöktürme ve solvent ekstraksiyon aşamalarını içeren prosesler yaygın olarak kullanılmaktadır. Nd-Fe-B mıknatıslar, nikel-metal hidrür piller ve lamba fosforları önemli ikincil NTE kaynakları olarak değerlendirilmektedirler. Bu atıklardan NTE'nin kazanımında inorganik asitlerin kullanıldığı liç yöntemleri yaygın olarak uygulanmaktadır.
Özellikle hibrit ve elektrikli araçların, rüzgâr türbinlerin ve floresan lambaların kullanımının yaygınlaşmasıyla beraber bu elementlere olan talep gelecekte hızlı bir şekilde artacaktır. $\mathrm{Bu}$ gerekçelerle, artan kritik hammadde talebi ve tüketimini karşılayabilmek için birincil kaynaklar dışında ikincil kaynaklardan da NTE gibi kritik hammaddelerin geri kazanımına/dönüşümüne yönelik faaliyetlerin artması öngörülmektedir.

\section{Kaynaklar}

Abrahami, S. T., Xiao, Y. and Yang, Y. (2015). Rareearth elements recovery from post-consumer hard-disc drives. Mineral Processing and Extractive Metallurgy, 124(2), 106-115. https://doi.org/10.1179/1743285514Y.00000000 84 
Akıska, E., Karakaş, Z. and Öztürk, C. (2019). Uranium, thorium and rare earth element deposits of Turkey. F. Pirajno, T. Ünlü, C. Dönmez, M.B. Şahin (Ed.), Mineral Resources of Turkey (s. 655-679). Springer. https://doi.org/10.1007/9783-030-02950-0_14

Akkurt, S., Topkaya, Y. and Ozbayoglu, G. (1993). Extraction of rare earths from a Turkish ore. Physicochemical Problems of Mineral Processing, 27, 68-76.

Anderson, L. (1986). Occurrence and processing of rare earth minerals, Erzmetall, 39(4), 152-157.

Bandara, H. M. D., Field, K. D. and Emmert, M. H., 2016. Rare earth recovery from end-of-life motors employing green chemistry design principles. Green Chemistry, 18,753-759. https://doi.org/10.1039/C5GC01255D.

Behera, S. S. and Parhi, P. K. (2016). Leaching kinetics study of neodymium from the scrap magnet using acetic acid. Separation and Purification Technology, $\quad 160, \quad 59-66$. https://doi.org/10.1016/j.seppur.2016.01.014.

Binnemans, K., Jones, P. T., Blanpain, B., Van Gerven, T., Yang, Y., Walton, A. and Buchert, M. (2013). Recycling of rare earths: A critical review. Journal of Cleaner Production, 51, 1-22. https://doi.org/10.1016/j.jclepro.2012.12.037.

Borra, C. R., Mermans, J., Blanpain, B., Pontikes, Y., Binnemans, K. and Gerven, T. V. (2016). Selective recovery of rare earths from bauxite residue by combination of sulfation, roasting and leaching. Minerals Engineering, 92, 151-159. https://doi.org/10.1016/j.mineng.2016.03.002.

Chan, T. N. (1992). A new beneficiation process for the treatment of supergene monazite ore. Rare Earths: Extraction. Preparation and Applications. TMS and AusIMM, San Diego, 7794.

Cheng, T. W. (2000). The point of zero charge of monazite and xenotime. Minerals Engineering, 13(1), 105-109. https://doi.org/10.1016/S08926875(99)00153-3

Cheng, T. W., Holtham, P. N. and Tran, T. (1993). Froth flotation of monazite and xenotime. Minerals Engineering, 6(4), 341-351.

Cheng, T. W., Partridge, A. C., Tran, T. A. M. and Wong, P. L. M. (1994). The surface properties and flotation behaviour of xenotime. Minerals Engineering, $\quad 7(9), \quad$ 1085-1098. https://doi.org/10.1016/0892-6875(94)90001-9.

Connelly, N. G., Damhus, T., Hartshorn, R. M. and Hutton, A. T. (2005). Nomenclature of Inorganic
Chemistry: IUPAC Recommendations 2005. Royal Society of Chemistry.

Croat, J. J., Herbst, J. F., Lee, R. W. and Pinkerton, F. E. (1984). Pr-Fe and Nd-Fe-based materials: A new class of high-performance permanent magnets (invited). Journal of Applied Physics, 55(6), 2078-2082.

Dai, S. and Finkelman, R. B. (2018). Coal as a promising source of critical elements: Progress and future prospects. International Journal of Coal Geology, $\quad 186, \quad 155-164$. https://doi.org/10.1016/j.coal.2017.06.005.

De Michelis, I., Ferella, F., Varelli, E. F. and Veglio, F. (2011). Treatment of exhaust fluorescent lamps to recover yttrium: experimental and process analyses. Waste Management, 31, 2559-2568.

Dostal, J. (2017). Rare earth element deposits of alkaline igneous rocks. Resources, 6(34), 1-2.

Du, X. and Graedel, T. E. (2011). Global rare earth inuse stocks in $\mathrm{NdFeB}$ permanent magnets. Journal of Industrial Ecology, 15(6), 836-843. https://doi.org/10.1111/j.15309290.2011.00362.x

Dushyanthaa, N., Batapolaa, N., Ilankoonb, I. M. S. K., Rohithaa, S., Premasiria, R., Abeysinghea, B., Ratnayakea, N. and Dissanayake, K. (2020). The story of rare earth elements (REEs): Occurrences, global distribution, genesis, geology, mineralogy and global production. Ore Geology Reviews, 122, 103521.

Erust, C., Akcil, A., Tuncuk, A., Deveci, H. and Yazici, E. Y. (2019). A Multi-stage process for recovery of neodymium $(\mathrm{Nd})$ and dysprosium (Dy) from spent hard disc drives (HDDs). Mineral Processing and Extractive Metallurgy Review, https://doi.org/ 10.1080/08827508.2019.1692010

European Commission, (2017). Critical raw materials, in the communication on the list of critical raw materials 2017. Erişim adresi https://eurlex.europa.eu/legal-content/.

European Commission, (2019). Recovery of critical and other raw materials from mining waste and landfills. Erişim adresi https://ec.europa.eu/jrc/en/publication/recoverycritical-and-other-raw-materials-mining-wasteand-landfills.

Ferron, C. J., Bulatovic, S. M. and Salter, R. S. (1991). Beneficiation of rare earth oxide mineral. Material Science Forum, 251-270.

Franus, W., Wiatros-Motyka, M. M. and Wdowin, M. (2015). Coal fly ash as a resource for rare earth elements. Environmental Science and Pollution 

$\begin{array}{lcc}\text { Research, } & 22, & 9464-9474 . \\ \text { https://doi.org/10.1007/s11356-015-4111-9. }\end{array}$

Gao, L. and Chen, Y. (2010). A study on the rare earth ore containing scandium by high gradient magnetic separation. Journal of Rare Earths, 28(4), 622-626. https://doi.org/10.1016/S10020721(09)60167-8.

Greinacher, E. (1981). History of rare earth applications, rare earth market today: Overview. In Gschneidner, Jr., K.A. (ed.), Industrial Applications of Rare Earth Elements ACS Symposium Series (pp. 3-18). Washington, DC 164, American Chemical Society.

Gschneidner, K.A. (1990). Physical properties of rare earth metals. Bulletin Alloy Phase Diagrams, 11, 216-224.

Gschneidner, K. A., Beaudry, B. J. and Capellen, J., 1995. Rare earth metals, ASM Metals Handbook, (s. 720-732). Metals Park, OH, ASM International.

Gschneidner, K. A. and Daane, A. H. (1988). Physical metallurgy. Gschneidner, K.A. and Eyring, L. (eds.), Handbook on the Physics and Chemistry of Rare Earths, (s. 409-484). North Holland, Amsterdam.

Gschneidner, K. A. (2011a). Globalization and the Sustainability of the Rare Earths, Materials Engineering 220, Iowa State University, Ames, IA.

Gschneidner, K. A. (2011b). The rare earth crisis-The supply and demand situation for 2010-2015. Material Matters, 6(2).

Guy, P. J., Bruckard, W. J. and Vaisey, M. J. (2000). Beneficiation of Mt weld rare earth oxides by gravity concentration, flotation, and magnetic separation. Seventh Mill Operators' Conference (pp. 197-205). AusIMM, Kalgoorlie.

Habib, K. and Wenzel, H. (2014). Exploring rare earths supply constraints for the emerging clean energy technologies and the role of recycling. Journal of Cleaner Production, 84, 348-359. https://doi.org/10.1016/j.jclepro.2014.04.035.

Haque, N., Hughes, A., Lim, S. and Vernon, C. (2014). Rare earth elements: overview of mining, mineralogy, uses, sustainability and environmental impact. Resources, 3(4), 614-635. https://doi.org/10.3390/resources3040614.

Hassoy, H. (2007). Nadir Toprak Elementleri Alaşımlı Sabit Miknatısl Rulo Tipi Kuru Manyetik Ayırıcılarda İşlem Parametreleri ile Ayırım Performansı Arasındaki İlişkilerin Incelenmesi, Doktora Tezi, Hacettepe Üniversitesi, Fen Bilimleri Enstitüsü, Ankara.
Hedrick, J. B., Sinha, S. P. and Kosynkin, V. D. (1997). Loparite, a rare-earth ore (Ce, Na, $\mathrm{Sr}, \mathrm{Ca})(\mathrm{Ti}$, $\left.\mathrm{Nb}, \mathrm{Ta}, \mathrm{Fe}^{+3}\right) \mathrm{O}_{3}$. Journal of Alloys and Compounds, 250, 467-470. https://doi.org/10.1016/S0925-8388(96)028241.

Higashiyama, Y. and Asano, K. (2007). Recent progress in electrostatic separation technology. Particulate Science and Technology, 16(1), 7790. https://doi.org/10.1080/02726359808906786.

Hoogerstraete, T. V., Blanpain, B., Gerven, T. V. and Binnemans, K. (2014). From NdFeB magnets towards the rare-earth oxides: A recycling process consuming only oxalic acid. RSC Advances, 109(4), 64099-64111.

Houot, R., Cuif, J. P., Mottot, Y. and Samama, J. C. (1991). Recovery of rare earth minerals with emphasis on flotation process. Siribumrungsukha, B., Arrykul, S., Sanguan Sai, P., Pungrassami, T., Sikong, L. and Kooptarnon, K. (Ed.), Proceedings of the International Conference of Rare Earth Minerals and Minerals for Electronic Uses (ss. 301-324). Hat Yai, Thailand.

Hua, Z. (2016). Rare earth recycling from NdFeB. Encyclopedia of Inorganic and Bioinorganic Chemistry, John Wiley \& Sons, Ltd.

Icin, K. (2016). Nd-Fe-B Esasll Sert (Kallcl) Miknatısların Melt Spinning Yöntemiyle Üretimi, Yapısal ve Manyetik Özelliklerinin İncelenmesi, Yüksek Lisans Tezi, Karadeniz Teknik Üniversitesi Fen Bilimleri Enstitüsü, Trabzon.

Ito, S., Yotsumoto, H. and Sakamoto, H. (1991). Magnetic separation of monazite and xenotime. Proceedings of the International Conference on Rare Earth Minerals and Minerals for Electronic Uses (pp. 279-299). Prince Songkla University, Hat Yai, TH.

Jackson, W. D. and Christiansen, G. (1993). International strategic minerals inventory summary report-Rare earth oxides. , Denver, CO: U.S. Geological Survey Circular 930-N, U.S. Geological Survey, Map Distribution.

Jha, M. K., Kumari, A., Panda, R., Kumar, J. R., Yoo, K. and Lee, J. Y. (2016). Review on hydrometallurgical recovery of rare earth metals. Hydrometallurgy, $\quad 165, \quad 2-26$. https://doi.org/10.1016/j.hydromet.2016.01.035.

Jiake, L. and Xiangyong, C. (1984). Research into the recovery of high-grade rare-earth concentrate from Baotou complex iron ore, China. IMM and Chinese Society of Metals PRC (Ed.), Processing, Mineral and Metallurgy, Extractive (s. 663-675). Kunming, Yunnan Province. 
Jiang, Y. R., Shibayama, A., Liu, K. and Fujita, T. (2004). Recovery of rare earths from the spent optical glass by hydrometallurgical process. Canadian Metallurgical Quarterly, 43, 431-438. https://doi.org/10.1179/cmq.2004.43.4.431.

Jiang, Y.R., Shibayama, A., Liu, K.J. and Fujita, T. (2005). A hydrometallurgical process for extraction of lanthanum, yttrium and gadolinium from spent optical glass. Hydrometallurgy, 76, 19.

https://doi.org/10.1016/j.hydromet.2004.06.010.

Jordens, A., Cheng, Y. P. and Waters, K. E. (2013). A review of the beneficiation of rare earth element bearing minerals. Minerals Engineering, 41, 97114.

https://doi.org/10.1016/j.mineng.2012.10.017.

Kanazawa, Y. and Kamitani, M. (2006). Rare earth minerals and resources in the world. Journal of Alloys and Compounds, 408-412, 1339-1343. https://doi.org/10.1016/j.jallcom.2005.04.033.

Kashiwakura, S., Kumagai, Y., Kubo, H. and Wagatsuma, K. (2013). Dissolution of rare earth elements from coal fly ash particles in a dilute $\mathrm{H}_{2} \mathrm{SO}_{4}$ solvent. Open Journal of Physical Chemistry, 3(2), 69-75. doi: 10.4236/ojpc.2013.32009.

Kosynkin, V. D., Moiseev, S. D., Peterson, C. H. and Nikipelov, B. V. (1993). Rare earths industry of today in the commonwealth of independent states. Journal of Alloys and Compounds, 192(12), 118-120. https://doi.org/10.1016/09258388(93)90204-Z.

Krishnamurthy, N. and Gupta, C. K. (2016). Extractive Metallurgy of Rare Earths (Second Edition). CRC Press-Taylor \& Francis Group.

Kul, M., Topkaya, Y. ve Karakaya, I. (2008). Rare earth double sulfates from pre-concentrated bastnasite, Hydrometallurgy, 93(3-4), 129-135. https://doi.org/10.1016/j.hydromet.2007.11.008.

Kumar, V., Jha, M. K., Kumari, A., Panda, R., Kumar, J. R. and Lee, J. Y. (2014). Recovery of rare earth metals (REMs) from primary and secondary resources: A review. EPD Congress-2014, (TMS). San Diego, California.

Kursun, İ. and Terzi, M. (2018). Distribution of trace elements in coal and coal fly ash and their recovery with mineral processing practices: A review, Journal of Mining \& Environment, 9(3), 641-655.

Kurşun, İ., Özdemir, O., Tombal, T. D., Terzi, M. and Hacıfazlığlu, H. (2017). Bastnazit Kompleks Cevherinden (Eskişehir, Türkiye) Bazı Nadir Toprak Elementlerinin (Ce, Nd, La) Asit Liçi ile Çözünürlüklerinin Araştırılması. Çukurova
Üniversitesi Mühendislik Mimarlı Fakültesi Dergisi, 32(1), 207-214.

Kurşun, I. and Terzi, M. (2018). Isparta çanaklı cevherinden sülfürik asit liçi ile NTE ekstraksiyonunun deneysel tasarımı. Bilimsel Madencilik, 57(4), 267-280.

Kurşunoğlu, S., Top, S., Hussaini, S., Gökçen, H. S., Altiner, M., Ozsarac, S. and Kaya, M. (2020). Extraction of Lanthanum and Cerium from A Bastnasite Ore by Direct Acidic Leaching. Bilimsel Madencilik, 59(2), 85-92.

Kuzmin, V. I., Pashkov, G. L., Lomaev, V. G., Voskresenskaya, E. N. and Kuzmina, V. N. (2012). Combined approaches for comprehensive processing of rare earth metal ores. Hydrometallurgy, 129-130, 1-6.

Li, F., Wang, J. and Zeng, X. (1988). A process for the recovery of $\mathrm{RE}$ minerals with a chelating collector. Bautista, R.G. and Wong, M.M. (Ed.), Rare Earths, (s. 71-79). Warrendale, PA: The Minerals, Metals and Materials Society.

Li, J., Chen, Z., Shen, B., Xu, Z. and Zhang, Y. (2017). The extraction of valuable metals and phase transformation and formation mechanism in roasting-water leaching process of laterite with ammonium sulfate. Journal of Cleaner Production, $\quad 140, \quad 1148-1155$. https://doi.org/10.1016/j.jclepro.2016.10.050.

Long, K. R., Van Gosen, B. S., Foley, N. K. and Cordier, D. (2010). The Principal Rare Earth Elements Deposits of the United States-A Summary of Domestic Depositsand a Global Perspective. Reston, VA, USA: U.S. Geological Survey Scientific Investigations Report 2010-5220, 1104.

Long, K. R., Van Gosen, B. S., Foley, N. K. and Cordier, D. (2012). The principal rare earth elements deposits of the United States: a summary of domestic deposits and a global perspective. Sinding-Larsen, R., Wellmer, F.-W. (Eds.), Nonrenewable Resource Issues: Geoscientific and Societal Challenges (s.131-155). Netherlands: Springer.

Lyman, J. W. and Palmer, G. R. (1993). Recycling of neodymium iron boron magnet scrap. Report of Investigations 9481. United States Bureau of Mines.

Lyman, J. W. and Palmer, G. R. (1993). Recycling of rare earths and iron from $\mathrm{NdFeB}$ magnet scrap. High Temperature Material Processes, 11(1-4), 175-187. https://doi.org/10.1515/HTMP.1993.11.1-4.175.

McGill, I. (2000). Rare earth elements. W.-V.V.G., \& C. KGaA (Eds.), Ullmann's Encyclopedia of 
Industrial Chemistry. Weinheim, Germany: Wiley-VCH Verlag GmbH \& Co. KGaA.

Menad, N. (1999). Cathode ray tube recycling. Resources, Conservation and Recycling, 26, 143154. 3449(98)00079-2.

Moustafa, M. I. and Abdelfattah, N. A. (2010). Physical and chemical beneficiation of the Egyptian Beach Monazite. Resource Geology, 60(3), 288$299 . \quad$ https://doi.org/10.1111/j.17513928.2010.00131.x.

MTA, (2017). Dünya'da ve Türkiye'de nadir toprak elementleri, Fizibilite Etütleri Daire Başkanlı̆̆l, Maden Serisi 5, 24s.

Onal, M. A. R., Aktan, E., Borra, C. R., Blanpain, B., Gerven, T. V. and Guo, M. (2017). Recycling of NdFeB magnets using nitration, calcination and water leaching for REE recovery. Hydrometallurgy, 167, 115-123.

Onal, M. A. R., Borra, C. R., Guo, M., Blanpain, B. and Gerven, T. V. (2015). Recycling of NdFeB magnets using sulfation, selective roasting, and water leaching. Journal of Sustainable Metallurgy, 1,199-215. https://doi.org/10.1007/s40831-015-0021-9.

Özbayoglu, G. and Atalay, U. M. (2000). Beneficiation of bastnaesite by a multi-gravity separator. Journal of Alloys and Compounds, 303-304, 520523. https://doi.org/10.1016/S09258388(00)00639-3.

Parthasarathy, P. and Bulbule, K. A. (2019). Recovery of rare earth elements from spent hard disc drive magnets- urban mining suitable for developing countries. American Journal of Engineering Research (AJER), 8(1), 137-145.

Rabatho, J. P., Tongamp, W., Takasaki, Y., Haga, K. and Shibayama, A. (2012). Recovery of Nd and Dy from rare earth magnetic waste sludge by hydrometallurgical process. Journal of Material Cycles and Waste Management, 15, 171-178. https://doi.org/10.1007/s10163-012-0105-6.

Rademaker, J. H., Kleijn, R. and Yang, Y. (2013). Recycling as a strategy against rare earth element criticality: A systemic evaluation of the potential yield of NdFeB magnet recycling. Environmental Science and Technology, 47, 10129-10136.

Reisdörfera, G., Bertuol, D. and Tanabe, E. H. (2019). Recovery of neodymium from the magnets of hard disk drives using organic acids. Minerals Engineering, $\quad 143, \quad 105938$. https://doi.org/10.1016/j.mineng.2019.105938.
Resende, L. V. and Morais, C. A. (2010). Study of the recovery of rare earth elements from computer monitor scraps-leaching experiments. Minerals Engineering, 23, 277-280. https://doi.org/10.1016/j.mineng.2009.12.012.

Rosenblum, S. and Brownfield, I. K. (1999). Magnetic Susceptibilities of Minerals. Erişim adresi https://pubs.usgs.gov/of/1999/ofr-990529/MAGRPTfinal.pdf

Sadri, F., Nazari, A. M. and Ghahreman, A. (2017). A review on the cracking, baking and leaching processes of rare earth element concentrates. Journal of Rare Earths, 35(8), 739-752. https://doi.org/10.1016/S1002-0721(17)609712.

Sagawa, M., Fujimura, S., Yamamoto, H. and Matsuura, Y. (1984). Permanent Magnet Materials Based on the Rare Earth Iron Boron Tetragonal Compounds. Journal of Applied Physics, 55(6), 2083-2087.

Shaw, K. G., Smutz, M. and Bridger, G. L. (1954). A process for separating thorium compounds from monazite sands. Springfield, VA: U.S. Atomic Energy Commission Report ISC-407, National Technical Information Service.

Straka, P. and Žežulka, V. (2019). Linear structures of Nd-Fe-B magnets: Simulation, design and implementation in mineral processing-A review, Minerals Engineering, 143, 105900. https://doi.org/10.1016/j.mineng.2019.105900.

Svoboda, J. (2004). Magnetic Techniques for the Treatment of Materials. Dordrecht / Boston / London: Kluwer Academic Publishers.

Svoboda, J. and Fujita, T. (2003). Recent developments in magnetic methods of material separation. Minerals Engineering, 16, 785-792. https://doi.org/10.1016/S0892-6875(03)002127.

Taggart, R. K., King, J. F., Hower, J. C. and Hsu-Kim, H. (2017). Rare earth element recovery from coal fly ash by roasting and leaching methods. Paper Presented at the World of Coal Ash (WOCA) Conference, Lexington, KY.

Tan, Q., Li, J. and Zeng, X. (2015). Rare Earth Elements Recovery from Waste Fluorescent Lamps: A Review. Critical Reviews in Environmental Science and Technology, 45, 749-776. https://doi.org/10.1080/10643389.2014.900240.

Topkaya, Y. and Akkurt, S. (1999). Acid Curing and Baking of Bastnaesite Ore and Concentrate, Materials Science Forum. Switzerland: Trans Tech Publications. 
Tran, T. (1991). New Developments in the Processing of Rare Earths. International Conference on Rare Earth Minerals and Minerals for Electronic Uses (s. 337-353). Prince Songkla University, Hat Yai, TH.

Tumbaz, E. (2019). Kişisel Görüşme, Eng Mineral Separation Technologies.

U.S. Geological Survey, 2019. Rare Earth Elements in Coal and Coal Fly Ash, Fact Sheet 2019-3048.

USGS (U.S. Geological Survey), (2016). Minerals yearbook. Erişim adresi http://minerals.usgs.gov/minerals/pubs/.

USGS (U.S. Geological Survey), 2020. Mineral Commodity Summaries 2020. Erişim adresi https://pubs.usgs.gov/periodicals/mcs2020/mcs2 020.pdf.

Vijayan, S., Melnyk, A. J., Singh, R. D. and Nuttall, K. (1989). Rare earths: their mining, processing, and growing industrial usage. Mining Engineering, $41,13-8$

Yang, Y., Walton, A., Sheridan, R., Guth, K., Gauß, R., Gutfleisch, O., Buchert, M., Steenari, B.M., Gerven, T. V., Jones, P. T. and Binnemans, K. (2017). REE recovery from end-of-life NdFeB permanent magnet scrap: A critical review Journal of Sustainable Metallurgy, 3, 122-149. https://doi.org/10.1007/s40831-016-0090-4.

Y1ld1z, N. (2016). Nadir toprak elementleri. Ankara: Dijital Yayın.

Yoshida, T., Ono, H. and Shirai, R. (1995). Recycling of used Ni-MH rechargeable batteries, Minerals, Metals \& Materials Society, 145-152.

Žežulka, V., Straka, P. and Mucha, P. (2005). The permanent $\mathrm{NdFeB}$ magnets in the circuits for magnetic filters and the first technological tests. International Journal of Mineral Processing, 78, 31-39.

https://doi.org/10.1016/j.minpro.2005.07.004.

Zhang, G., Luo, D., Deng, C., Lv, L., Liang, B. and Li, C. (2018). Simultaneous extraction of vanadium and titanium from vanadium slag using ammonium sulfate roasting-leaching process. Journal of Alloys and Compounds, 742, 504-511. https://doi.org/10.1016/j.jallcom.2018.01.300.

Zhang, J. and Edwards, C. (2012). A review of rare earth mineral processing technology. 44th Annual Meeting of the Canadian Mineral Processors (s. 79-102). CIM, Ottawa.

Zhang, P. W., Yokoyama, T., Itabashi, O., Wakui, Y., Suzuki, T. M. and Inoue, K. (1998). Hydrometallurgical process for recovery of metal values from spent nickel metal hydride secondary batteries. Hydrometallurgy, 50, 61-75. https://doi.org/10.1016/S0304-386X(98)000462.

Zhang, P. W., Yokoyama, T., Itabashi, O., Wakui, Y., Suzuki, T. M. and Inoue, K. (1999). Recovery of metal values from spent nickel-metal hydride rechargeable batteries. Journal of Power Sources, 77, 116-122. https://doi.org/10.1016/S0378-7753(98)001827.

Zhu, Z., Pranolo, Y. and Cheng, C. Y. (2015). Separation of uranium and thorium from rare earths for rare earth production-a review. Minerals Engineering, 77, 185-196. https://doi.org/10.1016/j.mineng.2015.03.012 